\title{
BLANQUEO DE CAPITALES SU PREVENCIÓN EN EL ORDENAMIENTO JURÍDICO CHILENO*
}

\author{
THE PREVENTION OF MONEY LAUNDERING IN THE CHILEAN \\ LEGAL SYSTEM*
}

ÁNGela Toso MiLOs**

\begin{abstract}
RESUMEN: El objetivo del presente trabajo es realizar un somero análisis acerca de las medidas de prevención de blanqueo de capitales aplicables en la actualidad a una serie de sujetos que intervienen en la actividad económica en Chile. Creemos que una labor de este tipo es necesaria, considerando la gran cantidad de normativa generada durante los últimos años en esta materia. Así, a través de este estudio, pretendemos abordar su contenido e intentaremos su sistematización.
\end{abstract}

Palabras clave: Lavado de dinero, lavado de activos, colocación, enmascaramiento, integración, prevención

ABSTRACT: The purpose of this paper is to make a brief analysis about the Chilean antimoney laundering regime, which considers a wide range of measures applicable to different actors of the local economic activity. We think that a work of this kind is necessary, considering the substantial regulation that has been generated during the last years in this matter. In this study, we will make a brief summary of its content and try out its systematization.

Key words: Money Laundering, placement, layering, integration, prevention.

\section{INTRODUCCIÓN}

A través de este trabajo pretendemos dar cuenta de las medidas de prevención de blanqueo de capitales aplicables en la actualidad a una serie de sujetos que intervienen en la actividad económica en Chile. Consideramos que el tratamiento de este tema es relevante, tomando en cuenta que, durante los últimos años, se ha generado gran cantidad de regulación en este ámbito ${ }^{1}$.

\footnotetext{
* Este trabajo ha sido elaborado en el marco del proyecto titulado "La prevención del blanqueo de capitales en el crédito documentario transferible. El "conocimiento del cliente" del banco emisor", financiado por la Dirección General de Investigación y Postgrado (DGIP) de la Universidad Católica del Norte, Antofagasta, Chile.

** Licenciada en Derecho Universidad Diego Portales, Doctoranda en Derecho, Universidad de Salamanca, España. Profesora de Derecho Comercial, Universidad Católica del Norte, Antofagasta, Chile. Dirección de correo electrónico: antoso@ucn.cl

${ }^{1}$ Ello responde a la rápida evolución normativa que suele observarse en esta materia a nivel mundial. Así, se ha señalado que: "Although money laundering was not recognized by any nation as a separate criminal offence until 1986, it has since become one of the most dynamic areas of the world's anti-crime effort" (NOBLE y COLUMBiC, 1997-1998, p. 80).
} 
Para lograr nuestro cometido, comenzaremos explicando el fenómeno del lavado de activos, cómo puede llevarse a cabo y algunas de sus principales características.

Ello permitirá entender por qué este fenómeno ha sido afrontado no solo desde una perspectiva represiva, en tanto figura sancionada por el Derecho penal, sino que también desde la de su prevención, tanto a nivel internacional como local.

Será este último ámbito el que abordaremos, formulando los lineamientos generales de lo que constituye el conjunto de medidas que han de ser aplicadas para la prevención del blanqueo de capitales en nuestro país. En este sentido nos referiremos, en primer lugar, a aquellas contempladas en la Ley 19.913, que rige esta materia. Finalmente, revisaremos las formulaciones que se han realizado por organismos como la Superintendencia de Valores y Seguros, la de Bancos e Instituciones Financieras, la de Casinos de Juego y la de Administradoras de Fondos de Pensiones. A lo anterior habrá que agregar la actividad desplegada en este ámbito por la Unidad de Análisis Financiero.

Según tendremos la oportunidad de apreciar, la mayoría de estos instrumentos viene a aclarar ciertos aspectos en relación con la aplicación de las disposiciones contenidas en la Ley 19.913. Sin embargo, esta regulación también incorpora nuevos deberes, que vienen a reforzar aquellos establecidos por la Ley.

\section{BLANQUEO DE CAPITALES. PROCESO DE EJECUCIÓN. PRINCIPALES CARACTERÍSTICAS DEL FENÓMENO EN LA ACTUALIDAD}

El blanqueo de capitales, lavado de activos o de dinero ${ }^{2}$ es un proceso $^{3}$ cuyo objeto es disimular el verdadero origen de aquellas rentas provenientes de actividades ilícitas 4 . Así, la necesidad de blanquear dinero surge cuando no es posible justificar su procedencia porque es la contraprestación a la ejecución de una actividad delictiva. Ello obliga a quienes acumulan grandes cantidades de dinero de origen ilícito a encontrar las vías que le permitan introducirlo en lo que podría llamarse "circuito monetario", de modo que pue-

\footnotetext{
2 Existe una serie de denominaciones utilizadas por la doctrina y las legislaciones de los diversos países para referirse a este delito. Sin embargo, las expresiones "blanqueo de capitales", "lavado de activos" o "lavado de dinero" son los más frecuentes. Ello en razón de la carga semántica que conllevan, que implica que cualquier persona puede comprender su significado, lo que ayuda a la función motivadora del tipo penal. PRAMS (2005) p. 20.

${ }^{3}$ En este sentido, nos adherimos a lo sostenido por el Grupo de Acción Financiera (GAFI), al considerar el blanqueo de capitales como un "proceso", en que la "limpieza" del dinero no se logra en forma instantánea, sino de manera progresiva a través de unas etapas más o menos complejas. Véase en este ámbito, el sitio web de GAFI www.fatf-gafi.org y FABIÁN (1998) pp. 51-54.

${ }^{4}$ Es posible encontrar a nivel doctrinario y legislativo múltiples definiciones de blanqueo de capitales, diferenciándose unas de otras en el elemento que, a juicio del autor que se trate, es de mayor importancia para caracterizar esta actividad delictiva. Algunas formulaciones existentes a este respecto pueden ser encontradas en FABIÁN (1998) pp. 46-48; GÓMEZ (1996) p. 21; y, BLANCO (2002) pp. 92-101. Si bien, el debate acerca de cuál es la noción más adecuada en este sentido nos parece del mayor interés e importancia, en razón de las limitaciones fijadas en relación con la extensión del presente trabajo, nos inclinaremos por definir el blanqueo de capitales de la forma señalada, que corresponde al concepto elaborado por GAFI, disponible en su sitio web, que hemos apuntado en la nota anterior de este trabajo.
} 
dan obtener una rentabilidad sin justificar su procedencia ${ }^{5}$. Junto con este propósito, se encuentra muchas veces el de ocultar la identidad del verdadero propietario de los fondos que se pretenden lavar, con la finalidad de dificultar la persecución penal y asegurar la impunidad de los participantes en los delitos que han generado el dinero sucio.

Se puede sostener que el dinero en el proceso de blanqueo suele seguir distintas etapas con independencia de la complejidad de la operación que se trate, las que denominaremos "colocación", "enmascaramiento" e "integración”, respectivamente ${ }^{6}$. Estas tres fases pueden llevarse a cabo separada o simultáneamente, aunque a menudo se superponen. La elección de alguna de ellas por parte de los delincuentes, dependerá, entre otros factores, de sus necesidades, de los mecanismos de lavado de activos disponibles en un determinado momento ${ }^{7}$, así como de las vulnerabilidades existentes en el ordenamiento jurídico en que se pretende(n) llevar a cabo la(s) operación(es) de reciclaje.

El objetivo de quienes blanquean capitales en la primera de las etapas indicadas ("colocación"), es deshacerse materialmente de las importantes sumas en efectivo que genera su actividad delictiva. Ello se lleva a cabo, normalmente, trasladando materialmente el dinero a una localidad distinta de aquella en que se recaudó, e introduciéndolo a continuación, en establecimientos financieros (bancos, casas de cambio...) o en otro tipo de negocios de muy variada condición. En este contexto, se destacan como métodos comunes de colocación los siguientes: a) fraccionamiento de sumas elevadas en otras múltiples de menor monto, con el objeto de burlar los mecanismos de control (información) establecidos en la mayoría de los países para aquellas operaciones que superan una determinada cuantía ${ }^{8}$; b) complicidad con el propio personal, por ejemplo, de las entidades de crédito; c) utilización abusiva de las normas que permiten a los sujetos obligados por los deberes de prevención de blanqueo de capitales de eximirse de la obligación de identificar determinadas actividades o categorías de personas, o bien una aplicación flexible del deber de conocimiento de los clientes; y d) la presentación de documentos falsos para enmascarar el origen o titularidad de los fondos?

La segunda etapa del proceso de blanqueo, denominada "enmascaramiento" o "estratificación”, tiene como objetivo desligar los dineros ilícitos de su origen, generando para ello un "...complejo sistema de amontonamiento de transacciones financieras encaminado a borrar la huella contable de tales fondos ilícitos"10. Algunos de los métodos utiliza-

\footnotetext{
${ }^{5}$ Montalvo (1995) p. 84.

${ }^{6}$ Este esquema de las fases en que se desarrolla el blanqueo de capitales es aquel mantenido por GAFI y es actualmente seguido mayoritariamente por la doctrina especializada en materia de prevención de lavado de activos, cual es el caso de Álvarez y EgUidazu (1997) pp. 33-41; y, RiCHARds (1998) pp. 47-49. Sin embargo este esquema no es el único que se ha formulado en este ámbito. En este sentido, BlANCO (2002) pp. 55-79, realiza una detallada descripción de los modelos más importantes formulados por la doctrina a la fecha.

7 BLANCO (2002) p. 63

${ }^{8}$ Pese a la aplicación de estas medidas en los sistemas de prevención de los distintos países, aún se siguen apreciando en la actualidad numerosos casos de blanqueo en que se ha logrado vulnerar este mecanismo de control. En este sentido, véase GAFISUD (2005) p. 25.

9 Álvarez y Eguidazu (1997) pp. 35-36.

10 Álvarez y Eguidazu (1997) p. 37.
} 
dos en esta fase son: a) la conversión del dinero en metálico en otros instrumentos o medios de pago; b) la reventa de bienes adquiridos con dinero en efectivo; y c) la transferencia electrónica o telegráfica de fondos depositados en un banco a otras cuentas situadas en zonas geográficas diversas ${ }^{11}$.

Por último la tercera y última etapa que se puede reconocer en el proceso de lavado de activos se denomina "integración” y consiste en conferir una apariencia definitiva de legalidad a un patrimonio de origen criminal, situando los fondos blanqueados en la economía de tal forma que, integrándose en el sistema bancario, aparecen como producto de una actividad comercial normal. Llegados a este estadio, los dineros de origen delictivo son ya muy difíciles de detectar. A menos que se haya podido seguir su rastro a través de las etapas anteriores, resultará sumamente complejo distinguir los capitales de origen ilegal de los de origen legal. Algunos de los métodos utilizados en esta fase son los siguientes: a) venta de bienes inmuebles ${ }^{12}$; b) constitución de sociedades "pantalla” y préstamos simulados ${ }^{13}$; y c) generación de facturas falsas de importaciónexportación ${ }^{14}$.

Existe consenso en señalar que la mayor posibilidad de detectar el dinero sucio se encuentra en la fase de "colocación" precedentemente descrita ${ }^{15}$, de modo que la mayoría de las medidas de prevención están orientadas hacia esta etapa del blanqueo. Ello por cuanto, en las restantes fases se hace necesario un esfuerzo adicional por parte de las autoridades para rastrear el origen delictivo de los fondos, en tanto estos han sido sometidos previamente por los delincuentes a diversas técnicas que dificultan esta tarea.

Para efectos de enfrentar adecuadamente la lucha contra el lavado de activos, en los últimos años, se ha intentado dibujar las principales características de esta actividad, poniendo de relieve que se trata de un fenómeno de gran volumen, a cargo de organizaciones profesionales y de carácter internacional ${ }^{16}$.

\footnotetext{
${ }^{11}$ Este es probablemente el método más importante de enmascaramiento utilizado por los blanqueadores de capitales. Las ventajas que el mismo les ofrece son evidentes: la rapidez, la reducción al mínimo de los rastros contables, la distancia a la que se pueden remitir rápidamente los fondos, y el anonimato en que se desenvuelven estas operaciones (que se acentúa al perderse estas dentro de la inmensa masa de transferencias que diariamente se ejecutan en el mundo). A ello se añade el desarrollo de las tecnologías, que intensifica estos rasgos, especialmente los relativos a la rapidez de las operaciones y a las dificultades de identificación de los titulares. ÁLVAREZ y EGUIDAZU (1997) p. 38.

${ }^{12}$ La compraventa de bienes inmuebles es uno de los vehículos más habituales, de blanqueo de fondos de origen ilícito como, simplemente, de ocultamiento de fondos sustraídos a la Hacienda Pública. Se trata de bienes relativamente líquidos, y su valor real es muy difícil de estimar, de forma que no resulta fácil para las autoridades fiscales determinar si el precio declarado de la compraventa coincide o no con el efectivamente pagado por el comprador. ÁLVAREZ y EGUIDAZU (1997) p. 39.

13 Por mediación de una sociedad pantalla una persona puede prestarse a sí misma fondos de origen ilícito. Los dineros que así recibe aparecen legalmente como procedentes de un préstamo al exterior. ÁLVAREZ y EGUIDAZU (1997) p. 39. Sobre la importancia y modalidades que adopta el uso de estructuras corporativas para el blanqueo de capitales, véase GAFI (2006) pp. 3-21.

14 Sobre esta técnica de lavado de activos y los efectos que produce sobre el comercio internacional, puede consultarse KENNEDY (2003) P. 143-144.

15 Álvarez y Eguidazu (2007) P. 29.

16 Estas características son destacadas, entre otros, por ÁlvareZ y EgUIDAZU (2007) P. 22-23, y por BLANCO (2002) P. 51.
} 
Considerando las grandes cantidades que son "lavadas"17, las operaciones de blanqueo de capitales suelen tener estructuras complejas (con la participación de numerosas empresas y personas situadas en diversos países), sofisticadas y de rápida evolución, de modo que sea prácticamente imposible descifrarlas y, en consecuencia, perseguir los fondos cuyo origen se intenta ocultar ${ }^{18}$. Es así como es común que tras las actividades de money laundering se encuentren organizaciones especializadas o "profesionales" en la comisión de los delitos que generan el dinero sucio, así como en su blanqueo ${ }^{19}$, las que muchas veces actúan asesoradas por contadores, economistas, informáticos, abogados, entre otros profesionales, para el logro de sus objetivos ${ }^{20}$.

Respecto de la última de las características asociada al fenómeno del blanqueo de capitales que hemos apuntado, esto es la internacionalización de las actividades de lavado, esta se ha configurado, fundamentalmente, a partir de la globalización de la economía mundial ${ }^{21}$. Dicha característica implica, en términos prácticos, que en la actualidad, es inusual que el dinero sucio sea blanqueado en el mismo lugar donde se originó. Ello por cuanto, el desplazamiento de los fondos de un país a otro dificulta su persecución por parte de las autoridades y facilita por tanto su encubrimiento ${ }^{22}$. En este sentido, las

17 No es fácil evaluar con precisión el volumen de los fondos procedentes de actividades delictivas que son objeto de lavado de activos. Se han realizado importantes esfuerzos en este ámbito, sin que a la fecha se haya podido cumplir en forma completamente satisfactoria con este objetivo. Reconociendo este hecho, tomaremos en consideración la estimación realizada por GAFI. Dicho organismo, sobre la base de estudios realizados por el Fondo Monetario Internacional, estima que los fondos blanqueados anualmente podrían situarse en un rango que va desde los 590 billones hasta 1.5 trillones de dólares. En este sentido, se puede consultar el sitio web de GAFI, ya apuntado en el presente trabajo.

18 Sin embargo, se ha estimado que "...la existencia de operaciones de blanqueo de gran envergadura tiene con frecuencia un elemento de vulnerabilidad. Blanquear grandes sumas de dinero sin dejar rastro ninguno no es ciertamente fácil. Y basta con frecuencia que caiga un solo eslabón en la compleja cadena del blanqueo para que a través de él pueda ser posible desarticular toda una red'. ÁLVAREZ y EGUIDAZU (1997) p. 29. Esta circunstancia, en nuestra opinión, justifica la existencia de normas de prevención del blanqueo aplicables a distintos sectores de la sociedad, ya que cada uno de los participantes, principalmente del sistema financiero, puede contribuir desde su función, a desbaratar el complicado entramado que, por su elevado volumen, implican las operaciones de lavado de activos.

19 La "profesionalización" de las organizaciones criminales surge “...debido a la necesidad de minimizar riesgos de persecución penal y de maximizar oportunidades. Para lograr tales fines surgen una serie de exigencias: la primera consiste en invertir grandes recursos en el análisis de riesgos y su gestión; la segunda se refiere a la aplicación de mayores recursos para el empleo de tecnología; y por último, se requiere invertir más recursos para profesionalizar el ciclo del blanqueo-inversión” BLANCO (2002) p. 52.

20 Sobre la actuación de profesionales especializados en blanqueo de dinero que están al servicio de las organizaciones criminales, véase MATTHERS (2004).

21 En este sentido, compartimos lo sostenido por Álvarez y EGUIDAZU, quienes señalan que “...En los últimos años se han acelerado procesos de integración regional, como la Unión Europea, el NAFTA o MERCOSUR, que implican una mayor facilidad de movimientos de personas, mercancias, servicios y capitales. Los históricos acuerdos del GATT han dado paso a una Organización Mundial de Comercio que busca la liberalización de los intercambios comerciales. En suma, la corriente internacional discurre por una senda de mayor de libertad de movimiento que, aunque indiscutiblemente positiva, tiene la inevitable consecuencia de facilitar las actividades de blanqueo” ÁlVAREZ y EGUIDAZU (1997) p. 30.

${ }^{22}$ Álvarez y EGUidaZu (2007) p. 28. 
denominadas "organizaciones criminales transnacionales" (en adelante "OCT") 23 suelen escoger, principalmente, para realizar la primera etapa del lavado de activos, aquellos países que cuentan con una legislación débil de prevención y persecución penal del delito de blanqueo de capitales, esto es, especialmente (mas no exclusivamente), los denominados "paraísos fiscales" 24 . También suelen focalizar sus actividades en aquellas zonas geográficas que no poseen herramientas efectivas de colaboración y coordinación entre las autoridades encargadas de la prevención y persecución del lavado de activos. Por su parte, las OCT intentan actuar simulando ser personas naturales o jurídicas que operan en el ámbito internacional con fondos lícitos, comportándose y sirviéndose, con la mayor naturalidad posible (esto es evitando despertar sospechas sobre su carácter criminal) de las oportunidades comerciales y jurídicas de negocios que los distintos ordenamientos y el mercado mundial brinda a las entidades legítimamente constituidas.

\section{REACCIÓN NORMATIVA FRENTE AL BLANQUEO DE CAPITALES}

\section{SU PREVENCIÓN}

Considerando las características de la actividad de blanqueo precedentemente expuestas y las consecuencias que conlleva para la economía ${ }^{25}$, a partir de 1980, la comunidad internacional tomó conciencia de que el lavado de activos es “...un fenómeno patológico de gran volumen, que amenaza pilares fundamentales de la sociedad occidental y en consecuencia requería de la debida preocupación por parte de los legisladores de los

\footnotetext{
${ }^{23}$ Las OCT se han convertido en uno de los mayores actores en la actividad económica global y se puede decir que constituyen una combinación entre lo empresarial y lo criminal, siendo un "espejo de las empresas transnacionales". Sin embargo, existen diferencias importantes entre ambos tipos de organizaciones. Entre ellas, destaca la doctrina, que unas solicitan permiso para operar en el territorio de un Estado, mientras que las otras acceden sin consentimiento, y evaden cualquier esfuerzo por interceptar sus actividades. BlANCO (2002) p. 38. Por su parte, FABIÁN establece, como características actuales de las OCT, la conexión que existe entre ellas. Dentro de las OCT más "connotadas" se encuentran, por ejemplo, la mafia italiana, la mafia rusa, la Yakusa japonesa, las triadas chinas, los carteles de Medellín y Cali, entre otros. FABIÁN (1998) p. 41. Sobre las OCT indicadas (y otras) y su forma de operar véase, RICHARDS (1998) pp. 3-31; Blanco (2002) pp. 40-50; y, Lilley (2005) pp. 20-28.

${ }^{24}$ Se trata de zonas geográficas que aplican regímenes fiscales de escasa o nula tributación, y que en consecuencia son utilizados por sociedades o particulares de otros países para domiciliar sociedades instrumentales en cuyas arcas ingresan sus beneficios. En realidad el problema planteado por estos países o zonas geográficas no es que impongan una baja fiscalidad, sino que aplican reglamentaciones extremadamente laxas a las entidades financieras operantes en ellos, ejercen una supervisión mínima sobre las mismas, y permiten y facilitan el anonimato en las operaciones. De ahí que sean un eslabón fundamental en la cadena de blanqueo de capitales. Ello explica que muchos países contemplen con prevención -e incluso impongan normas de supervisión y control especiales- a las transacciones e inversiones con origen o destino en los "paraísos fiscales" ÁlvVAREZ y EGUidAZU (1997) p. 30. La reglamentación destinada a la prevención del blanqueo de capitales en Chile establece medidas en este ámbito, las que tendremos oportunidad de evidenciar más adelante en el presente trabajo.

25 Entre ellas se cuentan los cambios inexplicables en la demanda de dinero, el riesgo para la solidez bancaria y el incremento de la volatilidad de los flujos de capital y el tipo de cambio debido a imprevistos movimientos de capital entre países. También puede afectar al valor de las propiedades en los lugares donde se invierte el dinero ilegal. Sobre las consecuencias económicas asociadas al fenómeno de blanqueo de capitales, véase DEL CID (2007) pp. 24-26.
} 
distintos paises" ${ }^{26}$. En este contexto surgió la Recomendación del Consejo de Europa de $1980^{27}$. Luego se formularon, la Declaración de Principios de Basilea ${ }^{28}$ para prevenir la utilización del sistema financiero para el blanqueo de fondos procedentes del crimen organizado $^{29}$ aprobada por los gobernadores de los Bancos Centrales del Grupo de los $\operatorname{Diez}^{30}$ y la Convención de las Naciones Unidas contra el tráfico ilícito de estupefacientes y sustancias psicotrópicas (en adelante "Convención de Viena") ${ }^{31}$, ambas de diciembre de $1988^{32}$. Estos documentos constituyen los primeros antecedentes de la lucha internacional contra el blanqueo de capitales.

26 Paralelamente, en esa época, Estados Unidos había llegado al convencimiento del fracaso de su sistema de lucha contra el blanqueo de capitales debido, fundamentalmente, a la internacionalización del sistema financiero que permitía lavar en el resto de los países los capitales que se habían generado por actividades ilícitas en el territorio americano. Así, EEUU fue el principal impulsor de la internacionalización y uniformidad de las medidas de prevención y represión de blanqueo a través de la incorporación de las mismas a los ordenamientos jurídicos nacionales (ÁLVAREZ y EGUIDAZU, 2007, p. 44).

27 Recomendación No R (80) 10, de 27. 6. 1980, del Comité de Ministros del Consejo de Europa, a los Estados miembros, relativa a medidas contra la transferencia y el encubrimiento de capitales de origen ilegal. Tales medidas se encuadraban dentro del máximo respeto al principio de secreto bancario y profesional, que únicamente debía quebrarse ante un proceso penal y con las garantías de una decisión judicial. Álvarez y Eguidazu (1997) p. 55.

28 El Comité de Basilea es un grupo nacido en 1974 e integrado por los directores de bancos centrales de Bélgica, Canadá, Francia, Alemania, Italia, Japón, Países Bajos, Suecia, Reino Unido y Estados Unidos, Suiza y Luxemburgo. Su objetivo es establecer criterios uniformes para la banca mundial que aseguren la confiabilidad en el sistema financiero. Al respecto véase www.bis.org (última visita al sitio web, 4.4.2008). Sus decisiones no tienen fuerza legal, pero son aplicadas sistemáticamente por la Superintendencia de Bancos e Instituciones Financieras en Chile. En este sentido, véase el Capítulo 1-14, sección I, de la Recopilación de Normas de dicho organismo supervisor.

29 El texto de la declaración establecía en términos amplios el deber de identificación del cliente bancario, el cumplimiento de las leyes tanto en las actividades realizadas por la banca en su propio nombre como cuando actúa en representación de sus clientes, el deber de cooperación de las autoridades encargadas del cumplimiento de las leyes (jueces y administración), y la formación del personal bancario en materia de prevención de blanqueo de capitales, entre otros temas. Para mayores detalles sobre el contenido de esta declaración puede consultarse ÁlvareZ y EGUIDAZU (2007) pp. 63-68; y, BLANCO (2002) pp. 166-167.

30 El Grupo de los Diez estaba integrado, al igual que actualmente, por Alemania, Bélgica, Canadá, Estados Unidos, Francia, Italia, Japón, Países Bajos, Reino Unido y Suecia, más Suiza. Fondo MonETARIO INTERNACIONAL (2005) disponible en www.imf.org.

31 Vigente en Chile a contar de 20 de agosto de 1990, fecha de su publicación en el Diario Oficial. Otros tratados internacionales elaborados posteriormente en este ámbito por la Organización de las Naciones Unidas, son el convenio internacional para la represión de la financiación del terrorismo de 2000, publicado en el Diario Oficial con fecha 13 de septiembre de 2002 y convención de las Naciones Unidas contra la delincuencia organizada transnacional (conocida como la "Convención de Palermo") de 2000, publicada en el Diario Oficial con fecha 16 de febrero de 2005. En relación con las iniciativas internacionales antiblanqueo, también debemos destacar la labor desarrollada por la Organización de Estados Americanos (OEA) a través de la Comisión Interamericana para el control contra el abuso de drogas (CICAD), que contempla la elaboración y actualización del denominado Reglamento Modelo sobre delitos de lavado de activos relacionados con el tráfico ilícito de drogas y otros delitos graves, cuyas últimas modificaciones son del año 2005, así como el diseño de programas de capacitación, entre otras iniciativas. En este sentido véase www.cicad.oas.org (última visita al sitio, 19.12.2007).

32 A través de esta convención, los Estados se comprometen, entre otras cosas, a calificar como delitos penales ciertos supuestos que forman parte de lo que comúnmente se conoce como lavado de activos (artículo 3. 1. Convención). Cabe hacer presente las limitaciones derivadas del objeto de la convención, 
Posteriormente, en 1989, se creó el Grupo de Acción Financiera Internacional sobre el lavado de activos ("GAFI" o "FATF"33)34. En 1990, dicho organismo elaboró por vez primera el texto denominado Las Cuarenta Recomendaciones del GAFI sobre blanqueo de capitales, cuya última versión es del año 2003 ${ }^{35}$. También adoptó, en 2001, las denominadas Recomendaciones especiales sobre la financiación del terrorismo ${ }^{36}$, cuya última actualización corresponde al año 2004 ${ }^{37}$. Ambos instrumentos han sido de vital importancia para la elaboración de la regulación sobre lavado de activos ${ }^{38}$, por ejemplo, a nivel europeo ${ }^{39}$ y también para el ordenamiento jurídico chileno ${ }^{40}$.

que implica que solo considera capitales ilícitos aquellos provenientes de actividades relacionadas con drogas. Para mayores detalles acerca de este tratado internacional, véase ÁlVVREZ y EGUIDAZU (2007) pp. 60-66; y, BLANCO (2002) pp. 98-107.

${ }^{33}$ Siglas que corresponden a su denominación en inglés Financial Action Task Force on Money Laundering.

${ }^{34}$ ESPín (1991) p. 1. 174. En relación con los antecedentes y contexto internacional en que el GAFI fue creado, así como los aspectos principales de su actividad, véase PALMA (2000) pp. 37-46; ROLDÁN (2001) pp. 203-212; y el sitio web del GAFI.

35 Desde su elaboración en 1990, las Cuarenta Recomendaciones del GAFI han sido revisadas en dos oportunidades. La primera en 1996 y la segunda el 2003, texto al cual haremos referencia en el presente estudio. Estas recomendaciones se estructuran en los siguientes apartados: A. Sistemas jurídicos (recomendaciones 1 a 3); B. Medidas que deben tomar las instituciones financieras y actividades y profesiones no financieras para impedir el lavado de activos y el financiamiento del terrorismo (recomendaciones 4 a 25); C. Medidas institucionales y de otros tipos necesarias en los sistemas destinados a combatir el lavado de activos y el financiamiento del terrorismo (recomendaciones 26 a 34); y, D. Cooperación internacional (recomendaciones 35 a 40).

36 Disponibles también en el sitio web de la organización. Sobre la gestación y primeras actividades del GAFI en relación con estas últimas recomendaciones, véase ZAGARIS (2002-2003) pp. 83-85.

37 Por su parte, GAFI ha diseñado también una metodología para el adecuado cumplimiento de sus recomendaciones, que se encuentra recogida en GAFI (2004), disponible en el sitio web de la organización.

${ }^{38}$ Dado que GAFI es un organismo con funciones de estudio y asesoramiento, no puede tomar decisiones ejecutivas con los efectos que tienen los convenios o tratados internacionales. Sin embargo, hay que decir que sus recomendaciones tienen en la práctica una fuerza de hecho a veces más importante que la fuerza jurídica que conllevan los instrumentos internacionales antes mencionados. Y ello porque se trata de un organismo en el que están integrados los países de mayor relevancia en materia financiera y que tienen intereses comunes en esta materia. ÁLVAREZ y EGUIDAZU (1997) pp. 46-52. Respecto de la fuerza y efectos de las decisiones del GAFI, puede consultarse también a ALEXANDER (2001) pp. 231-248; así como, JOHNSON y LiM (2002) pp. 7-22.

39 Prueba de ello es la intervención directa de la Unión Europea en la creación del GAFI, a través de la participación en ella del Presidente de la Comisión Económica Europea y de expertos comunitarios que colaboraron en el estudio de los aspectos financieros del blanqueo de capitales, según se acordó en la cumbre de París de 1989. Esta vinculación entre el GAFI y la Unión Europea persiste hasta hoy. En este contexto, resulta especialmente interesante comparar el texto de las mentadas recomendaciones con la Directiva comunitaria 2005/60/CE, de 26 de octubre de 2005, relativa a la prevención de la utilización del sistema financiero para el blanqueo de capitales y para la financiación del terrorismo, complementada por lo dispuesto en la Directiva 2006/70/CE, de 1 de agosto de 2006.

40 En el ámbito regional, Chile participa de GAFISUD. Este organismo fue creado a semejanza del GAFI adhiriéndose a sus Cuarenta Recomendaciones como estándar internacional contra el lavado de dinero más reconocido y a las Recomendaciones especiales sobre la financiación del terrorismo, previendo el desarrollo de recomendaciones propias de mejora de las políticas nacionales para luchar contra estos delitos. Uno de los observadores de GAFISUD es precisamente el GAFI. Acerca de este organismo, véase su sitio web www.gafisud.org. 
En razón de la internacionalidad y magnitud que reviste el fenómeno de blanqueo de capitales en la actualidad, este debe combatirse principalmente con medidas de carácter penal y en el marco de la cooperación internacional. Sin embargo, la estrategia de la lucha contra el lavado de activos no se limita al enfoque indicado. En efecto, el alto nivel de profesionalidad asociado a este delito, ha hecho necesaria la colaboración del sistema financiero, entre otros agentes de la sociedad, a fin de evitar que este ilícito se verifique. Así, "La lucha contra el blanqueo de capitales se debe hacer bajo un doble enfoque: utilizando un sistema represivo y un sistema preventivo. El sistema represivo consiste en castigar a aquellos que hayan incurrido en un delito de blanqueo de capitales. La investigación y persecución de este delito corresponde a los órganos policiales, judiciales y fiscales de los estados, y las infracciones y sanciones vienen recogidas en normativa de derecho penal ${ }^{41}$. El sistema preventivo tiene como misión establecer una serie de barreras o trabas para evitar que se produzca el delito de blanqueo de capitales. Tiene, por tanto, una función disuasoria, que se materializa en una serie de obligaciones dirigidas a aquellos sujetos que operan en sectores económicos sensibles al blanqueo de capitales" 42 . Este último aspecto de la lucha contra el blanqueo de capitales será aquel que constituirá el objeto de nuestro trabajo. Es así como enfocaremos este estudio en aquellas medidas de prevención de lavado de activos establecidas, particularmente, en el ordenamiento jurídico chileno.

\section{MARCO JURÍDICO DE LA PREVENCIÓN DEL BLANQUEO DE CAPITALES EN EL ORDENAMIENTO JURÍDICO CHILENO}

En nuestro país, la normativa sobre blanqueo de capitales está constituida, fundamentalmente, por el contenido de la ley $\mathrm{N}^{\circ} 19.913$ que crea la Unidad de Análisis

41 Esto último, en nuestro ordenamiento, se concreta en lo dispuesto en los artículos 27 y 28 de la Ley 19.913. A efectos de nuestro estudio, cabe hacer presente que la lucha contra el blanqueo de capitales, desde un punto de vista penal, en un principio, se orientó a combatir el lavado de aquellos fondos provenientes de actividades relacionadas con drogas. Sin embargo, en la actualidad los textos legales que apuntan a la prevención y sanción de este delito, al indicar los ilícitos generadores de los capitales cuyo blanqueo se sanciona, contemplan también otras figuras delictivas o bien cualquier participación en un delito sancionado con una determinada pena por el ordenamiento jurídico. En el caso del ordenamiento jurídico chileno, el artículo 27 de la Ley 19.913 contempla, dentro de los delitos "antecedentes" del de blanqueo, los hechos constitutivos de alguno de los delitos contemplados en la ley No 19.366, que sanciona el tráfico ilícito de estupefacientes y sustancias psicotrópicas; en la ley No 18. 314, que determina las conductas terroristas y fija su penalidad; en el artículo 10 de la ley No 17. 798, sobre control de armas; en el Título XI de la ley No 18. 045, sobre mercado de valores; en el Título XVII del decreto con fuerza de ley No 3, de 1997, del Ministerio de Hacienda, Ley General de Bancos; en los Párrafos 4, 5 , 6 y 9 del Título V del Libro II del Código Penal y, en los artículos 141, 142, 366 quáter, 367 y 367 bis del Código Penal. Desde la perspectiva de la prevención del lavado de activos, que constituye el objeto de nuestro estudio, la ampliación a nivel penal del abanico de delitos cubiertos por la figura del blanqueo, facilita a los sujetos afectados por los deberes de prevención, el cumplimiento de los mismos, principalmente el de reportar las operaciones sospechosas a las autoridades locales.

42 Villavieja (2007) p. 235. Ambos sistemas de lucha contra el blanqueo de capitales, el sistema represivo y el sistema preventivo, son complementarios, ya que con la información obtenida a través del sistema preventivo se pueden iniciar procedimientos de investigación de delitos de blanqueo de capitales para su posterior enjuiciamiento en vía penal. 
Financiero y modifica diversas disposiciones en materia de lavado y blanqueo de activos, publicada en el Diario Oficial con fecha 18 de diciembre de 2003 (a la que también llamaremos, en adelante, "la Ley") ${ }^{43}$.

Por su parte, las medidas de prevención de este delito se concretan, principalmente, en las disposiciones contenidas en el párrafo segundo de la Ley (artículos 3 a 7). Estas normas pretenden imponer determinadas obligaciones a operadores económicos que desarrollan su actividad, fundamentalmente, en el ámbito financiero, mas no exclusivamente en este ${ }^{44}$.

Por su parte, dicha regulación se ve complementada por aquella de carácter sectorial, emanada, por ejemplo, de organismos como la Superintendencia de Valores y Seguros 45 (en adelante "SVS"), la Superintendencia de Bancos e Instituciones Financieras $^{46}$ (en adelante "SBIF"), la de Casinos de Juego ${ }^{47}$ y la de AFP 48 . A lo anterior habrá que agregar la actividad desplegada en este ámbito por la Unidad de Análisis

43 Esta ley vino a derogar gran parte del contenido de la antigua Ley $\mathrm{N}^{\circ} 19.366$, sobre Tráfico Ilícito de Estupefacientes y Sustancias Psicotrópicas, hoy sustituida por la Ley 20.000, de 16 de febrero de 2005. Por su parte, esta fue modificada por la ley 20.119, de 31 de agosto de 2006 que, en lo fundamental, amplió las facultades de la Unidad de Análisis Financiero para el acceso a información y estableció sanciones por el incumplimiento de las obligaciones establecidas por estas leyes. Asimismo, incorporó a las Administradoras de Fondos de Pensiones (AFP) y a las sociedades anónimas deportivas profesionales, al grupo de personas naturales y jurídicas que tienen la obligación de reportar operaciones sospechosas y operaciones en efectivo superiores a 450 Unidades de Fomento, según lo establece el artículo 3o de la Ley No 19.913.

44 Cabe hacer presente que, si bien casi cualquier actividad económica puede ser utilizada con fines de blanqueo, es evidente que algunos sectores son más idóneos que otros para estas prácticas y constituyen en consecuencia campo preferente de la actividad de los lavadores de activos. Entre los más importantes se cuentan, las entidades del sistema financiero (entidades de crédito, compañías de seguros, corredoras de bolsa, etc.). Sin embargo, producto de que en materia de prevención se ha avanzado notablemente en los últimos años en el sistema financiero, los delincuentes han comenzado a buscar "nuevos horizontes" extendiendo su actividad también a otros sectores, como es el caso de los casinos de juego, las sociedades anónimas deportivas, las Administradoras de Fondos de Pensiones e incluso determinadas profesiones (abogados, contadores, etc.). De ello se deriva que el espectro de los "sujetos obligados" en materia de prevención de blanqueo de capitales se haya ampliado los últimos años.

45 En este sentido destacamos la Circular No 1809, de 10 de agosto de 2006, y la Circular No 1853 , de 2 de octubre de 2007, que modifica la primera.

46 Este organismo ha elaborado normativa destinada a la aplicación de las medidas de prevención del blanqueo de capitales en el sector financiero. Entre ellas se cuentan el Capítulo 1-14 de la Recopilación de Normas de la Superintendencia de Bancos e Instituciones Financieras, cuyo contenido fue fijado por la Circular No 3351 de dicho organismo, de 6 de marzo de 2006; las Circulares No 57 y 58, de 20 de julio de 2006, aplicable a las empresas de leasing y factoraje filiales de bancos; y, la Circular No 123 , de 6 de julio de 2006, aplicable a las cooperativas de ahorro y crédito.

47 En este ámbito dicha superintendencia ha elaborado la Circular No 3, de 23 de julio de 2007, conjuntamente con la Unidad de Análisis Financiero. Para este último servicio, dicha Circular aparece bajo el No 0024 .

48 A este respecto, véase la Circular No 1480, de 28 de diciembre de 2007, dictada conjuntamente con la Unidad de Análisis Financiero. Para este último servicio, dicha Circular aparece bajo el No 0036. Cabe hacer presente que el alcance de las medidas de prevención de lavado de activos contenidas en esta circular se circunscriben a las operaciones de los afiliados a las AFP cuya naturaleza sea voluntaria (depósitos y giros), sea que estas se realicen en forma habitual u ocasional. Ello excluye las cotizaciones o depósitos legales obligatorios aplicables a todo afiliado. 
Financiero ${ }^{49}$ (en adelante "UAF"), cuyo objetivo es prevenir e impedir la utilización del sistema financiero y otros sectores de la actividad económica para la comisión del delito de lavado o blanqueo de $\operatorname{activos}^{50}$.

Este régimen, pretende impedir la utilización del sistema económico chileno para el blanqueo de capitales, por lo que se aplica sin perjuicio de la legislación penal que tipifica dicho delito ${ }^{51}$.

49 Lo que se refleja en el contenido de las cerca de cuarenta circulares que, en cumplimiento de lo dispuesto en el artículo $2 \mathrm{f}$ ) de la ley 19.913, ha elaborado desde el 16 de abril de 2004, fecha en que este organismo inició sus funciones. Estos instrumentos pueden ser consultadas en la página web de este servicio, www. uaf. cl (última visita, 4.4.2008).

${ }^{50}$ Ello, según lo dispone el artículo 1 de la Ley 19.913. Se trata de un servicio público descentralizado, con personalidad jurídica y patrimonio propios que se relaciona con el Presidente de la República por medio del Ministerio de Hacienda. Para el cumplimiento de sus objetivos, el artículo 2 de la Ley 19.913 le ha fijado una serie de atribuciones, entre las que se cuentan: a) Solicitar, verificar, examinar y archivar la información sobre operaciones sospechosas de blanqueo de capitales; b) Solicitar a cualquiera de los sujetos obligados por la norma los antecedentes que con ocasión de la revisión de una operación sospechosa previamente reportada a la Unidad o detectada por esta en ejercicio de sus atribuciones, resulten necesarios y conducentes para desarrollar o completar el análisis de dicha operación; c) Disponer exámenes periciales, los que podrá encomendar a instituciones públicas o privadas; d) Organizar, mantener y administrar archivos y bases de datos, pudiendo integrarlos, con el debido resguardo y protección, a las redes de información nacionales e internacionales para el adecuado cumplimiento de sus funciones; e) Recomendar medidas a los sectores público y privado para prevenir la comisión del delito de lavado de activos; f) Impartir instrucciones de aplicación general a los sujetos obligados por la Ley 19.913, pudiendo en cualquier momento verificar su ejecución; g) Intercambiar información con sus similares del extranjero; h) Analizar, a lo menos una vez al año, los registros de operaciones en efectivo sobre las 450 Unidades de Fomento o su equivalente en otras monedas que han de mantener los sujetos obligados por la ley 19.913; i) Acceder, en la forma en que se convenga con el jefe superior de la entidad respectiva, a las informaciones y antecedentes existentes en las bases de datos de los organismos públicos que, con ocasión de la revisión de una operación sospechosa previamente reportada a la Unidad o detectada por esta en ejercicio de sus atribuciones, resulten necesarios y conducentes para desarrollar o completar el análisis de dicha operación y a los que deba recabar de conformidad con la letra g) indicada; $y, j$ ) Imponer las sanciones administrativas que establece la Ley 19.913. Cuando, del examen de los antecedentes referidos en las letras que anteceden, el Director de la Unidad de Análisis Financiero estime que aparecen indicios de que se ha cometido alguno de los delitos a que se refiere el artículo 27 de la ley, deberá disponer su inmediata remisión al Ministerio Público.

${ }^{51}$ Ello quiere decir que la obligación de colaboración impuesta por la legislación penal con carácter general en la Ley 19.913 afecta a cualquier ciudadano o empresario, con independencia de la actividad que realizan. Por el contrario, las obligaciones administrativas impuestas por la Ley 19.913 son obligaciones en función de una vinculación jurídica singular, a través de un sistema excepcional, y solo para el ámbito de aplicación previamente fijado por dicha ley. ÁLVAREZ y EGUIDAZU (1997) p. 131. En relación con estas últimas, el legislador ha estimado oportuno formular un régimen específico que recoja las clases de infracciones y sus respectivas sanciones, en el Título II de la Ley 19.913. Entre las sanciones contempladas por la Ley, en su artículo 20, se encuentran la amonestación y multas que van desde las 800 Unidades de Fomento (límite fijado por el legislador en caso de infracciones leves), hasta las 5.000 Unidades de Fomento (límite fijado por el legislador en caso de infracciones graves). Si bien las sanciones indicadas, en ciertos casos, pueden no resultar verdaderamente significativas para los sujetos obligados, no es menos cierto que una conducta contraria a la Ley 19.913 puede producir importantes consecuencias penales para los infractores, así como un daño en la reputación de los sujetos obligados, y provocarse así, eventualmente, una fuga de su clientela. Ello considerando que las sanciones aplicadas en este contexto, suelen ir acompañadas de una gran cobertura de prensa y en consecuencia suelen estar sometidas a la opinión pública. Ello podrá redundar en una importante pérdida económica (y eventualmente también para sus 


\subsection{LAS MEDIDAS DE PREVENCIÓN DEL BLANQUEO DE CAPITALES ESTABLECIDAS EN LA LEY 19.913}

Las medidas de prevención de lavado de activos establecidas por la Ley 19.913 han de ser adoptadas por determinadas personas, naturales o jurídicas, que desarrollan ciertas actividades que el legislador ha considerado sensibles al blanqueo de capitales ${ }^{52}$. Estos son los que denominaremos "sujetos obligados", y se encuentran contemplados en el artículo 3 inciso primero de dicho instrumento legal ${ }^{53}$.

El primer deber antiblanqueo aplicable a los sujetos obligados por la Ley, es el de informar las operaciones sospechosas de lavado de activos a la Unidad de Análisis Financiero $^{54}$. En este contexto, se formula una definición de operación sospechosa, señalándo-

empleados, directivos y/o gerentes) posiblemente mayor, que la que significa la aplicación de las sanciones señaladas. Esta circunstancia ha sido reconocida, entre otros, por la Superintendencia de Valores y Seguros, en su Circular $\mathrm{N}^{\circ} 1809$, sección $\mathrm{N}^{\circ} 1$, y por la Superintendencia de Bancos e Instituciones Financieras, según se desprende del Capítulo 1-14, sección I, de su Recopilación de Normas.

52 Sin embargo, nuestra legislación también establece deberes de prevención de aplicación más amplia, cual es el caso de aquel contemplado en el artículo 4 de la Ley 19.913, constituido por la obligación de informar que afecta a "... todo aquel que porte o transporte moneda en efectivo o instrumentos negociables al portador, desde y hacia el pais, por un monto que exceda los diez mil dólares de los Estados Unidos de América o su equivalente en otras monedas". Esta información es recabada directamente por el Servicio Nacional de Aduanas y remitida directamente por este a la UAF. Para estos efectos se ha elaborado un formulario de reporte (declaración de porte y transporte de efectivo o "DPTE”). En este sentido véase el sitio web de la UAF.

${ }^{53}$ Las medidas antilavado se aplican a un conjunto heterogéneo de actividades. Así, son "sujetos obligados" por la norma indicada, los siguientes: bancos e instituciones financieras; empresas de factoraje; empresas de arrendamiento financiero; las empresas de securitización; las administradoras generales de fondos y las administradoras de fondos de inversión; el Comité de Inversiones Extranjeras; las casas de cambio y otras entidades que estén facultadas para recibir moneda extranjera; las emisoras y operadoras de tarjetas de crédito; las empresas de transferencia y transporte de valores y dinero; las bolsas de comercio; los corredores de bolsa; los agentes de valores; las compañías de seguros; los administradores de fondos mutuos; los operadores de mercados de futuro y de opciones; las sociedades administradoras y los usuarios de zonas francas; los casinos, salas de juegos e hipódromos; los agentes de aduana; las casas de remate y martillo; los corredores de propiedades y las empresas dedicadas a la gestión inmobiliaria; los notarios; los conservadores las administradoras de fondos de pensiones, y las sociedades anónimas deportivas profesionales, regidas por la ley $\mathrm{N}^{\circ} 20.019$.

54 Ello de acuerdo con lo establecido en el artículo 3 de la Ley 19.913, que dispone que "Las personas naturales y las personas jurídicas que se señalan a continuación (“sujetos obligados”), estarán obligadas a informar sobre los actos, transacciones u operaciones sospechosas que adviertan en el ejercicio de sus actividades...”. Por su parte, y según se dispone en la Circular No 0008 de la UAF, de fecha 31 de mayo de 2006 (dirigida a todos los "sujetos obligados"), “...para un adecuado cumplimiento de la Ley 19.913, las operaciones sospechosas, una vez detectadas, deben ser inmediatamente reportadas o comunicadas a la Unidad de Análisis Financiero, siguiendo para ello los procedimientos e instrucciones de reporte que se han impartido y que se describen en el mismo sitio web”. En relación con el cumplimiento de esta medida de prevención por parte de los sujetos obligados, se ha evidenciado un creciente aumento de los reportes de operaciones sospechosas durante los últimos años. Así, la UAF ha señalado que, durante el año 2005, la UAF recibió y analizó un total de 153 reportes. En el año 2006, el número de reportes aumentó a 270, mientras entre enero y diciembre del 2007 la cantidad de reportes recibida y analizada por la UAF fue de 419 , lo que representa un incremento de 55\% respecto al año anterior. En cuanto a la proporción de envío de reportes por sujeto obligado, la mayor cantidad de estos durante el 2007 provino de los bancos (83\%), comportamiento similar al de unidades similares del extranjero. Desde el inicio de la obligación de enviar reportes a la UAF, esta ha recibido 895 reportes, de los cuales 140 han sido traspasados al Ministerio Público o al Consejo de Defensa del Estado. En este sentido véase el sitio web de la UAF. 
se que es "...todo acto, operación o transacción que, de acuerdo con los usos y costumbres de la actividad que se trate, resulte inusual o carente de justificación económica o jurídica aparente, sea que se realice en forma aislada o reiterada"55, 56. A estos efectos, se establece que será la UAF la encargada de señalar a los sujetos obligados “...las situaciones que especialmente habrán de considerarse como indiciarias de operaciones o transacciones sospechosas..." 57 . Ello se ha concretado en la elaboración por parte de dicho servicio, en mayo de 2006, de la guía Señales de alerta indiciarias de lavado o blanqueo de activos, para el sistema financiero y otros sectores ${ }^{58}$. En dicho documento se incluye "...un importante número de señales de alerta organizadas de acuerdo al tipo de transacción y a los sujetos o entidades en que pueda presentarse" 59 .

55 En este sentido, la Circular No 1809, sección $N^{\circ} 3$, de la Superintendencia de Valores y Seguros, establece que "Se deberá dar especial atención a aquellas que presenten elementos o características inusuales, irregulares o anormales, en relación con las actividades o giro del cliente o de cualquiera de los que participan en ella, y/o que por su gestación, diseño financiero, estructura, presentación, documentación utilizada, modificación de antecedentes ya registrados, información proporcionada o falta de esta, por la reiteración o cuantía de las mismas o la intervención inusual de terceros desconocidos".

56 Ello conforme lo dispone el artículo 3 inciso segundo, de la Ley 19.913. La formulación realizada por el legislador en este ámbito, constituye una manifestación de un sistema de prevención de blanqueo de capitales que puede sindicarse como "subjetivo", de modo tal que la calificación de una operación como "sospechosa" se basará, mayoritariamente, en el juicio de los sujetos obligados y sus empleados (NOBLE y COLUMBIC,1997-1998, p. 81). En este contexto, criticando el concepto de operación sospechosa formulado por el legislador señala "Bien puede concluirse que el concepto utilizado por el legislador resulta inconveniente, vislumbrándose más de algún problema futuro en su aplicación. Al efecto se desprenden de él las siguientes conclusiones: $1^{\circ}$. La "operación sospechosa" se determinará de acuerdo a los usos y costumbres de la actividad de que se trate. De este modo una misma operación podrá ser sospechosa para un sector y no para otro. $2^{\circ}$. Los usos y costumbres de la actividad son conceptos esencialmente imprecisos $y$, además, esencialmente cambiantes en el tiempo. Lo que hoy puede resultar inusual, mañana dejará de serlo. $3^{\circ}$. La caracteristica cambiante que poseen los usos y costumbres determina la existencia de un período de ajuste en que algo, que era considerado inusual deja de serlo, o a la inversa; periodo en que el concepto -ya impreciso- se hace sencillamente inalcanzable” MARTORELL (2003) p. 125.

57 Artículo 3 inciso cuarto de la ley 19.913.

58 Este documento fue dado a conocer a los sujetos obligados a través de la Circular No 0008 de la UAF, de fecha 31 de mayo de 2006, que puede ser consultada en el sitio web de dicho servicio. En esta comunicación se advierte que la guía “...no tiene un carácter taxativo, debiendo los sujetos obligados reportar todas aquellas operaciones que, por el propio conocimiento de su respectiva actividad y de sus propios clientes consideren sospechosas de conformidad a la ley”. Así, la Circular indicada establece que también deben considerarse como una orientación para la prevención y detección de operaciones sospechosas, los siguientes documentos: GAFISUD (2004) y (2005), ambos disponibles en www.gafisud.org (última visita al sitio web, 4.4.2008); GAFI (2001) y (2005), ambos disponibles en www.fatf-gafi.org (última visita al sitio web, 4.4.2008); y, GRUPO EGMONT (2000), disponible en www.egmontgroup.org (última visita al sitio web, 4.4.2008). Lo anterior debe complementarse con lo establecido en la Circular No 0025 de la UAF, de 13 de agosto de 2007 (dirigida a todos los "sujetos obligados"), que dispone que deberán reportarse como sospechosas cualquier acto, operación o transacción que realice alguna de las personas indicadas en la Lista del Comité 1267 del Consejo de Seguridad de las Naciones Unidas, sea de manera directa o a través de mandatarios, cualquiera que sea su monto. Esta nómina corresponde a un listado emitido por el Comité 1267 del Consejo de Seguridad de las Naciones Unidas, que individualiza a personas físicas y entidades miembros de los talibanes y de la organización Al-Qaida o asociados con ellos. Información obtenida del sitio web de la UAF.

59 UNidAd DE ANÁlisis FinANCIERO (2007) p. 4. 
La comunicación o reporte que se realice, deberá contener información respecto de la(s) operación(es) que se informa(n) y de los involucrados en ella(s), indicando los elementos que se tuvieron en consideración al definir la(s) operación(es) como sospechosa $(s)^{60}$. En relación con el cumplimiento de este deber, los sujetos obligados contemplados habrán de designar un funcionario responsable de relacionarse con la Unidad de Análisis Financiero ${ }^{61}$, que suele denominarse "Oficial de Cumplimiento" (Compliance Officer, en inglés) u "Oficial de Prevención de Lavado de Activos" (AntiMoney Laundering Officer, en inglés) ${ }^{62}$.

En este contexto, la Unidad de Análisis Financiero podrá solicitar a los sujetos obligados "...los antecedentes que con ocasión de la revisión de una operación sospechosa previamente reportada a la Unidad... resulten necesarios y conducentes para desarrollar o

${ }^{60}$ En este sentido véase el sitio web de la UAF. En él se contiene información en relación a la forma y el contenido de los reportes en relación con cada uno de los sujetos obligados.

${ }^{61}$ Ello conforme lo dispone el artículo 3 inciso 4 de la Ley 19.913.

62 Se trata de un ejecutivo de nivel alto, que ha de contar con la absoluta confianza de la administración de la institución que representa. Según lo ha dispuesto la UAF, todos los sujetos obligados deben informar a dicho servicio el Oficial de Cumplimiento designado. Ello a través de los mecanismos establecidos a estos efectos por dicho servicio. Según se ha indicado por la Unidad de Análisis Financiero, su función principal es "...la coordinación de las politicas y procedimientos de prevención y detección de operaciones sospechosas al interior de la empresas, como asimismo, responsabilizarse por el cumplimiento de las obligaciones contenidas en la Ley 19.913 y circulares emitidas por esta Unidad". Ello según se dispone en las Circulares de la Unidad de Análisis Financiero No 0018, de 11 de mayo de 2007 (dirigida a las casas de cambio, empresas de transferencia de dinero y empresas de transporte de valores y dinero); No 0020, de 14 de junio de 2007 (dirigida a las empresas de factoraje); No 0021, de 14 de junio de 2007 (dirigida a las empresas de arrendamiento financiero); No 0022, de 21 de junio de 2007 (dirigida a las cooperativas de ahorro y crédito); No 0024, de 23 de julio de 2007 (dirigida a los casinos); No 0026, de 16 de agosto de 2007 (dirigida a las administradoras de fondos de inversión); No 0027, de 16 de agosto de 2007 (dirigida a las administradoras de fondos mutuos); No 0028, de 16 de agosto de 2007 (dirigida a las administradoras generales de fondos); No 0029, de 16 de agosto de 2007 (dirigida a las compañías de seguros); No 0030, de 16 de agosto de 2007 (dirigida a los corredores de bolsa); No 0031, de 16 de agosto de 2007 (dirigida a los agentes de valores); No 0032, de 7 de septiembre de 2007 (dirigida a las emisoras de tarjetas de crédito y operadoras de las mismas); No 0033, de 30 de agosto de 2007 (dirigida a las empresas de securitización). En este sentido véase el sitio web de la UAF. Por su parte, la Circular $\mathrm{N}^{\circ} 1809$, sección $\mathrm{N}^{\circ} 6$, de la Superintendencia de Valores y Seguros, establece que el Oficial de Cumplimiento debe en la medida de lo posible, ser "... independiente de las áreas de negocios, auditoría y riesgo de la entidad financiera. El oficial de cumplimiento deberá detentar un nivel de responsabilidad gerencial y estar dotado de facultades y recursos suficientes para cumplir con sus funciones". Además, la Circular de la UAF No 0036, de 28 de diciembre de 2007 (dirigida a las Administradoras de Fondos de Pensiones), señala este deber en su número 3, en los términos indicados, sosteniendo además que el cargo de Oficial de Cumplimiento "...si bien es compatible con el cargo de gerente de un área no puede recaer en personas vinculadas a las áreas de riesgo, operativa y auditoría interna". Por su parte, el Capítulo 1-14, sección II. 4, de la Recopilación de Normas de la SBIF establece en este ámbito, que "El Oficial de Cumplimiento deberá ser un funcionario independiente de las áreas tomadoras de riesgo, operativa y de auditoría interna; tener un nivel gerencial, cuya función y responsabilidad principal será mantener una coordinación interna respecto de la vigilancia de las operaciones de los clientes con la entidad y sus filiales, la observancia de las instrucciones del manual de procedimientos, el conocimiento de los casos sospechosos y su comunicación al Comité de Prevención de Lavado de Activos y Financiamiento del Terrorismo. El banco deberá informar a esta Superintendencia el nombre, cargo y dependencia del Oficial de Cumplimiento, información que deberá mantenerse actualizada. De acuerdo al tamaño y naturaleza de la entidad, el Oficial de Cumplimiento deberá contar con recursos humanos y tecnológicos adecuados". 
completar el análisis de dicha operación... Las personas requeridas estarán obligadas a proporcionar la información solicitada, en el término que se les fije" 63 . En todo caso, "Las disposiciones legales, reglamentarias, contractuales o de cualquier otra indole sobre secreto o reserva de determinadas operaciones o actividades no impedirán el cumplimiento de la obligación de informar... Lo anterior es también aplicable si la Unidad solicita la entrega o exhibición de los antecedentes que el sujeto obligado tuvo en consideración para reportar la operación sospechosa"64. Así, se levantan restricciones como el secreto bancario, que podrían impedir el cumplimiento del deber de informar y la posibilidad de aportar antecedentes a la Unidad de Análisis Financiero en relación con las operaciones reportadas.

La segunda obligación aplicable a los sujetos indicados en el artículo 3 de la Ley 19.913, se desprende de lo dispuesto en su artículo 2 b). De acuerdo con esta norma, los sujetos obligados habrán de proporcionar a la UAF los antecedentes que, con ocasión de la revisión de una operación sospechosa detectada por aquella en el ejercicio de sus atribuciones, resulten necesarios y conducentes para desarrollar o completar el análisis de dicha operación o bien a efectos de compartir información con sus similares en el extranjero, en las condiciones señaladas en el artículo 2 g) de la Ley 19.913. Sin embargo, en el supuesto que se trate de antecedentes sujetos a secreto o reserva, o bien que deban solicitarse a un sujeto no obligado por la ley, la UAF deberá contar con la autorización previa del ministro de la Corte de Apelaciones de Santiago, que el Presidente de dicha Corte designe por sorteo en el acto de hacerse el requerimiento ${ }^{65}$.

La tercera obligación aplicable a los sujetos obligados es la de “...mantener registros especiales por el plazo minimo de cinco años, e informar a la Unidad de Análisis Financiero cuándo esta lo requiera, de toda operación en efectivo superior a cuatrocientas cincuenta unidades de fomento o su equivalente en otras monedas". A este respecto, la UAF ha indicado que "Se debe considerar como efectivo, para estos efectos, solo a aquellas operaciones que se materialicen mediante papel moneda o dinero metálico" 66.

63 Artículo 2 b) de la Ley 19.913. Ahora, conforme a la norma indicada, si los antecedentes que se solicitan estuvieren amparados por el secreto o reserva, o deban requerirse a una persona que no constituye un "sujeto obligado" por la ley, la solicitud de la UAF habrá de ser fundada y autorizada previamente por el ministro de la Corte de Apelaciones de Santiago, que el Presidente de dicha Corte designe por sorteo en el acto de hacerse el requerimiento.

${ }^{64}$ Artículo 3, inciso penúltimo, de la Ley 19.913.

65 Ello de acuerdo con el procedimiento establecido en el mismo artículo 2 b) de la Ley.

66 Artículo 5 de la ley 19.913. Esta información debe ser analizada, a lo menos, una vez al año por la Unidad de Análisis Financiero, según lo dispone el artículo 2 h) de la Ley 19.913. Este organismo ha emitido diversas circulares relacionadas con la aplicación de esta norma, cual es el caso de la Circulares No 0002, de 18 de mayo de 2005 (dirigida a las casas de cambio); No 0006, de 29 de septiembre de 2005 (dirigida a los bancos); No 0007, de 6 de marzo de 2006 (dirigida a los sujetos obligados distintos a los bancos y casas de cambio); No 0011, de 5 de septiembre de 2006 (dirigida a todos los sujetos obligados); No 0012, de 5 de septiembre de 2006 (dirigida a los bancos); No 0013, de 5 de septiembre de 2006 (empresas de transferencia y transportes de valores y dinero); No 0015, de 22 de noviembre de 2006 (dirigida a empresas de transporte de valores reguladas por el Decreto exento $\mathrm{N}^{\circ} 1.226$ del Ministerio del Interior; No 0016, de 28 de diciembre de 2006 (dirigida a los bancos); No 0017, de 8 de marzo de 2007 (dirigida a las casas de cambio); No 0019, de 22 de mayo de 2007 (dirigida a los sujetos obligados distintos a los bancos y casas de cambio); No 0023, de 11 de julio de 2007 (dirigida a los sujetos obligados distintos a los bancos y casas de cambio); No 0024, de 23 de julio de 2007 (dirigida a los casinos y 
En el contexto de los deberes de comunicación que hemos analizado, cabe hacer presente que, toda información que se entregue de buena fe "...eximirá de toda responsabilidad legal a quienes la entreguen"67. Con esta medida se busca proteger a los sujetos obligados y sus empleados, frente a sus clientes, incentivando la entrega de antecedentes a la Unidad de Análisis Financiero.

Para el adecuado cumplimiento de las obligaciones indicadas, el artículo 6 de la Ley 19.913 prohíbe, tanto a los sujetos obligados como a sus empleados, “...informar al afectado o a terceras personas, la circunstancia de haberse requerido o remitido información a la Unidad de Análisis Financiero, como asimismo, proporcionarles cualquier otro antecedente al respecto"68. Ello se aplicará también a las personas que presten servicios a cualquier título para los sujetos obligados, que hayan tenido conocimiento de la circunstancia de haberse requerido o remitido información a la $U_{A F}{ }^{69}$. Se trata de un estricto deber de confidencialidad impuesto a estas entidades cuya única justificación, a la vista de la relación recíproca que debe existir en todo caso entre los sujetos obligados y sus clientes, radica en la posible frustración de las actuaciones de las autoridades competentes en la lucha contra la delincuencia organizada ${ }^{70}$.

sociedades operadoras de casinos); $\mathrm{N}^{\circ} 0034$, de 25 de octubre de 2007 (dirigida a sujetos obligados no financieros, distintos a usuarios de zonas francas); y No 0035, de 19 de noviembre de 2007 (dirigida a todos los sujetos obligados). Según se desprende del contenido de las circulares indicadas, la UAF ha diseñado un mecanismo de reporte de estas operaciones, al que se accede a través del sitio web de la entidad. Esta obligación se aplica a con diversa periodicidad según el tipo de sujeto obligado. Cabe hacer presente que se debe completar la información solicitada en los formularios diseñados por dicho servicio a estos efectos. Finalmente, el deber de informar también ha de cumplirse en el caso que los sujetos obligados no hayan constatado la existencia de operaciones "reportables" durante el período que se trate. Ello se cristaliza en el envío de un "Registro de operaciones en efectivo negativo" (ROE negativo) a la Unidad de Análisis Financiero. Esta información se encuentra disponible en el sitio web de la UAF.

${ }^{67}$ Artículo 3, inciso final de la Ley 19.913.

${ }^{68}$ Artículo 6, inciso primero de la Ley 19.913.

69 Artículo 6, inciso final, de la Ley 19.913. Esta disposición regirá, tanto en el caso que se hayan reportado operaciones a la UAF, cuanto en el supuesto que dicho servicio requiera a los sujetos obligados antecedentes en relación con la revisión de una operación sospechosa previamente reportada o detectada por la Unidad de Análisis Financiero en el ejercicio de sus atribuciones, y que sean necesarios y conducentes para desarrollar o completar el análisis de dicha operación. También se deberá respetar esta prohibición en el caso que la UAF requiera información a los sujetos obligados a fin de intercambiar información con sus similares en el extranjero. Ello conforme lo dispone el artículo 6, en relación con el artículo 2 letra b) y g) de la Ley 19.913. En este último caso, la UAF deberá cerciorarse de que dicha información no será utilizada para fines diferentes y que la entidad solicitante operará con reciprocidad en caso que se le solicite información.

70 GUILLÉN (1997) p. 219. La infracción a la prohibición lleva aparejada una sanción penal. Así, el artículo 7 de la Ley 19.913 dispone que "La infracción a lo dispuesto en el artículo $6^{\circ}$ será castigada con la pena de presidio menor en sus grados medio a máximo y multa de cien a cuatrocientas unidades tributarias mensuales. La misma pena se aplicará a quienes, estando obligados de conformidad a esta ley a proporcionar información a la Unidad, maliciosamente destruyan, alteren u oculten los antecedentes o documentos que deban entregar, o entreguen antecedentes o documentos falsos". 


\subsection{OTRAS MEDIDAS DE PREVENCIÓN DE LAVADO DE ACTIVOS ESTABLECIDAS EN EL ORDENAMIENTO JURÍDICO CHILENO}

Según hemos señalado, nuestro sistema de prevención de lavado de activos se completa con el contenido de las circulares emitidas por la Unidad de Análisis Financiero, dictadas en cumplimiento de lo dispuesto en el artículo 2 e) y f) de la Ley $19.913^{71}$, así como con la regulación proveniente de los organismos supervisores de distintos sectores de la actividad económica nacional ${ }^{72}$. La mayoría de estos instrumentos viene a aclarar ciertos aspectos en relación con la aplicación de las disposiciones contenidas en la Ley 19.913 que hemos examinado, por lo que su elaboración es reciente, concentrándose esta, principalmente, en los últimos tres años ${ }^{73}$.

Sin embargo, esta regulación también incorpora nuevos deberes, que vienen a reforzar aquellos establecidos por la Ley. Se trata de medidas reconocidas desde hace ya tiempo por los organismos internacionales expertos en la materia e incorporadas en diversos ordenamientos jurídicos extranjeros ${ }^{74}$.

De conformidad con estos instrumentos, se establecen, como medidas de prevención, adicionales a las precedentemente expuestas, en primer lugar, la de conocer a los clientes (Know Your Customer o KYC, en inglés) ${ }^{75}$. Esta constituye la base de un

\footnotetext{
${ }^{71}$ A este respecto, véase la nota $\mathrm{N}^{\circ} 49$ de este trabajo.

72 En este sentido, véanse las notas No 45 a 48 de este estudio. Cabe hacer presente que la normativa de carácter sectorial se aplica en forma conjunta con aquella contemplada en las circulares de la UAF. Ello se deduce de lo dispuesto en las circulares de dicho servicio No 0020, de 14 de junio de 2007 (dirigida a las empresas de factoraje); No 0021, de 14 de junio de 2007 (dirigida a las empresas de arrendamiento financiero); y, No 0022, de 21 de junio de 2007 (dirigida a las cooperativas de ahorro y crédito) que establecen que en el caso que las entidades indicadas “... sean supervisadas por la Superintendencia de Bancos e Instituciones Financieras o por la Superintendencia de Valores y Seguros, las presentes instrucciones son complementarias a las emitidas por dichas superintendencias". Lo mismo se desprende de la lectura de la Circular No 3, sección $N^{\circ} 5$, de la Superintendencia de Casinos de Juego.

73 Es el caso de las Circulares de la UAF, que han sido dictadas, en su mayoría durante los años 2006 y 2007. En este sentido véase el sitio web de dicho servicio. Por su parte, tanto la Circular $\mathrm{N}^{\circ} 3$ de la Superintendencia de Casinos de Juego y como la $\mathrm{N}^{\circ} 1480$, de la Superintendencia de AFP son del año 2007. En el caso de la SVS, dicho organismo elaboró su primer instrumento en este ámbito el año 2003, cristalizándose este en el contenido de la Circular $\mathrm{N}^{\circ} 1680$, que fue luego sustituida por la $\mathrm{N}^{\circ} 1809$, de 10 de agosto de 2006, cuyo contenido analizaremos en este trabajo. Constituye una excepción en este ámbito el sector bancario, que ya en la década de los noventa, a través de la Asociación de Bancos e Instituciones Financieras, formuló recomendaciones para la prevención del lavado de activos. Por su parte, la Superintendencia de Bancos e Instituciones Financieras, en el año 2001, se sumó a esta actividad, incorporando en la Recopilación Actualizada de Normas el Capítulo 1-14 sobre Prevención de Lavado de Activos. Sin embargo, su texto actual también data del año 2006.

74 En este sentido véanse, por ejemplo, GAFI (2003); COMISIÓN INTERAMERICANA PARA EL CONTROL Contra El Abuso De Drogas (Cicad) (2005); y, Comité De Supervisión Bancaria De Basilea (2001). A nivel europeo, véanse, por ejemplo, el contenido de las Directivas 91/308/CE, de 10 de junio; 2001/97/CE, de 4 de diciembre (que modifica la primera); Directiva 2005/60/CE, de 26 de octubre, que deroga las anteriores, complementada por lo dispuesto en la Directiva 2006/70/CE, de 1 de agosto de 2006.

75 En términos generales, la existencia de una política $K Y C$ implica, al momento de iniciar una relación con un cliente, así como durante la vigencia de la misma, la obligación de contar con antecedentes suficientes que permitan sostener que el cliente es quien dice ser y que, en virtud de la información que se
} 
sistema efectivo antiblanqueo ${ }^{76}$. El cumplimiento adecuado de los deberes de información que impone la Ley 19.913, se encuentra estrechamente relacionado con el conocimiento que los sujetos obligados han de tener respecto de sus clientes. Así, solo será posible calificar una operación como sospechosa de blanqueo, si se cuenta con antecedentes suficientes, tanto de la propia transacción como de quienes participan en ella. Además, para efectuar las comunicaciones correspondientes, se requiere contar con los datos necesarios para sustentarlas, lo que supone un adecuado conocimiento respecto de los clientes ${ }^{77}$ y las operaciones que estos llevan a cabo. Se ha señalado que este deber no solo debe concebirse como una herramienta orientada a la prevención, sino

tiene sobre él (que permite determinar el nivel de riesgo de blanqueo que este implica para el sujeto obligado), no existen bases para creer que está envuelto en actividades de lavado de activos LILLEY (2005) p. 176. Sobre la importancia de esta medida de prevención del blanqueo, véase AlBA (2002) p. 139.

76 Así se ha reconocido en diversas Circulares de la Unidad de Análisis Financiero, que abordan esta medida de prevención, a saber, las Circulares No 0018, de 11 de mayo de 2007 (dirigida a las casas de cambio, empresas de transferencia de dinero y empresas de transporte de valores y dinero); No 0020, de 14 de junio de 2007 (dirigida a las empresas de factoraje); No 0021, de 14 de junio de 2007 (dirigida a las empresas de arrendamiento financiero); No 0022, de 21 de junio de 2007 (dirigida a las cooperativas de ahorro y crédito); No 0026 (dirigida a las administradoras de fondos de inversión); No 0027 (dirigida a las administradoras de fondos mutuos); No 0028 (dirigida a las administradoras generales de fondos); No 0029 (dirigida a las compañías de seguros); No 0030 (dirigida a los corredores de bolsa); No 0031 (dirigida a los agentes de valores), todas de 16 de agosto de 2007; No 0032, de 7 de septiembre de 2007 (dirigida a las emisoras de tarjetas de crédito y operadoras de las mismas); № 0033, de 30 de agosto de 2007 (dirigida a las empresas de securitización), todas disponibles en el sitio web de la UAF. La SVS también se refiere a la importancia de la política $K Y C$ en su Circular No 1809 , sección $N^{\circ}$ 2. y la SBIF lo hace en el Capítulo 1-14, sección II. 2, de su Recopilación de Normas. Por su parte, la Superintendencia de Casinos de Juego, en su Circular No 3, sección 2. A., también consagra el deber de conocimiento de los clientes. Finalmente la Circular No 1480, sección $\mathrm{N}^{\circ}$ 1, de la Superintendencia de AFP también recoge el deber de "conocimiento del afiliado". A través de los instrumentos indicados, se ha pretendido articular una política de conocimiento de los clientes respecto de los diversos sujetos obligados por la Ley 19.913, intentando dotarla de uniformidad.

${ }^{77}$ Lo primero que hemos de preguntarnos a fin de afrontar este tema es el alcance que cabe atribuir al concepto de "cliente" para efectos de aplicar este deber de prevención. En este sentido, el Capítulo 1-14, sección I., de la Recopilación de Normas de la SBIF, establece, que "....son clientes todas las personas naturales y juridicas con las cuales la entidad establece o mantiene una relación de origen legal o contractual, como consecuencia de la prestación servicio o contratación de un producto, ofrecido en el marco de las actividades propias de su giro y de conformidad a las disposiciones legales y reglamentarias. Esta relación puede ser ocasional o habitual". Similar definición de "cliente" encontramos en las Circulares de la UAF indicadas en la nota anterior, salvo el caso de la Circular $\mathrm{N}^{\circ}$ 0018, de 11 de mayo de 2007 (dirigida a las casas de cambio, empresas de transferencia de dinero y empresas de transporte de valores y dinero), que no se refiere expresamente a este punto. Por su parte, la Circular $\mathrm{N}^{\circ} 3$, sección 2., de la Superintendencia de Casinos de Juego, señala "Para estos efectos, se considerará cliente a toda persona natural con la cual el casino realice operaciones propias de su giro". Finalmente, la Circular $\mathrm{N}^{\circ} 1809$, sección $\mathrm{N}^{\circ} 2$, de la SVS dispone que "... por cliente se entiende toda persona natural o juridica con la que la entidad sujeto de la presente regulación crea, establece o mantiene una relación de origen contractual, a fin de obtener el primero la prestación de un servicio o contratación de un producto, ofrecido dentro del marco propio del giro exclusivo o complementario del segundo, conforme al marco legal y/o reglamentario, ya sea que la relación sea de carácter ocasional, esporádico, único, reiterado, frecuente o permanente". Hacemos el alcance que, en el caso de las AFP, no se utiliza la noción de cliente, sino que de "afiliado" y el deber de conocimiento se aplica, especialmente a "todo aquel que realice operaciones de depósito y giro de carácter voluntario". Ello según lo dispone la Circular No 1480, sección N 3, de la Superintendencia de AFP. 
que también como un mecanismo de gestión eficaz de los riesgos a los cuales está expuesta una entidad ${ }^{78}$.

En relación con los elementos constitutivos de una política de conocimiento del cliente $^{79}$, se ha considerado que, una estructura $K Y C$ adecuada conlleva, en ciertos casos, el establecimiento de un plan de aceptación de clientes ${ }^{80}$. Además requiere la completa identificación de los mismos y sus actividades, y el seguimiento permanente de las operaciones efectuadas por ellos ${ }^{81}$.

En cuanto al contenido del deber de identificación, la normativa antiblanqueo establece diversos requerimientos, dependiendo del sujeto obligado que se trate. Sin embargo, en general, se debe contar con datos de los clientes, como por ejemplo, nombre completo (en el caso de personas jurídicas se deberá registrar la razón social de la persona jurídica); sexo; nacionalidad; número de cédula nacional de identidad o número de pasaporte (se deberá exigir la exhibición de el o los documentos originales, debiendo el sujeto obligado conservar fotocopia de estos); profesión, ocupación u oficio y giro en el caso de personas jurídicas; dirección o residencia en Chile o país de origen o residencia; y, teléfono de contacto ${ }^{82}$.

Respecto de los casinos de juego, esta obligación será aplicable en el caso de transacciones por montos iguales o superiores a los US\$3.000 o su equivalente en otras monedas. En este sentido, se señala que esta obligación es aplicable, por ejemplo, a

78 Así se expresa en el Capítulo 1-14, sección II. 2., de la Recopilación de Normas de la SBIF. Idéntica visión de este deber de prevención se recoge en la Circular $\mathrm{N}^{\circ} 3$, sección $\mathrm{N}^{\circ} 2$, de la Superintendencia de Casinos de Juego. Lo mismo ocurre respecto de las circulares de la UAF indicadas en la nota $\mathrm{N}^{\circ} 76$ de este trabajo, salvo el caso de la Circular $\mathrm{N}^{\circ}$ 0018, de 11 de mayo de 2007 (dirigida a las casas de cambio, empresas de transferencia de dinero y empresas de transporte de valores y dinero), que no se refiere expresamente a este punto. También se trata este tema en la reciente Circular No 1480 , sección $\mathrm{N}^{\circ} 1$, de la Superintendencia de AFP

79 Para una exposición más detallada en relación con los elementos de una política KYC, véase ALBA (2002) pp. 137-140.

80 El Capítulo 1-14, sección II. 2, de la Recopilación de Normas de la SBIF señala, que “...el banco requiere la elaboración de políticas y procedimientos de aceptación (...) los que deberán tener en cuenta, entre otros factores, los antecedentes del cliente; perfiles de actividad; monto y origen de los fondos involucrados; el pais de origen de estos $y$ si dicho país cumple con los estándares minimos de aceptación exigidos; y sus relaciones societarias $u$ otros indicadores de riesgo. Si se trata de una persona de influencia a nivel internacional, deberá contar con la aprobación de la alta administración". La existencia políticas de aceptación de clientes, ligadas al conocimiento de los mismos se encuentra recogido en términos muy similares en las circulares de la Unidad de Análisis Financiero indicadas en la nota $\mathrm{N}^{\circ} 76$ de este trabajo, salvo el caso de la Circular $\mathrm{N}^{\circ}$ 0018, de 11 de mayo de 2007 (dirigida a las casas de cambio, empresas de transferencia de dinero y empresas de transporte de valores y dinero), que no se refiere expresamente a este punto. La normativa emanada de la SVS, Superintendencia de Casinos de Juego y de AFP no trata este tema.

81 En este sentido el GAFI (2003), Las Cuarenta Recomendaciones del GAFI sobre blanqueo de capitales, nota 6, p. 6, Recomendación 5 d), señala que las entidades obligadas deben "llevar a cabo un proceso continuo de debida diligencia respecto de la relación comercial, asi como un examen detallado de las operaciones realizadas durante todo el curso de esa relación, con el fin de asegurar que las operaciones que se están haciendo son compatibles con lo que la institución sabe del cliente, sus negocios y perfil de riesgo, incluso el origen de los fondos, en caso necesario". Por su parte, el deber de seguimiento continuo de cuentas y transacciones se encuentra recogido también en COMITÉ De Supervisión BANCARIa De BASILEA (2001) p. 19.

82 Ello conforme lo establecen las Circulares de la UAF indicadas en la nota $\mathrm{N}^{\circ} 76$ de este trabajo. 
"...la compra, por cualquier medio de pago, o canje por efectivo de fichas o cospeles del casino y cambio de divisas. Estas operaciones excluyen explicitamente a las operaciones de juego que involucran solamente fichas o cospeles del casino" 83 .

Respecto de las casas de cambio, empresas de transferencia de dinero y empresas de transporte de valores y dinero solo se requerirá esta información respecto de toda transacción por un monto igual o superior a US\$5.000 o su equivalente en otras monedas, ya sea en efectivo o en cualquier tipo de documento. Además, será necesario contar con una declaración suscrita o firmada por el solicitante de la operación en la cual de cuenta del origen y/o destino de los fondos involucrados en la misma ${ }^{84}$.

En materia bancaria, se realiza una distinción entre aquellos clientes que mantienen una cuenta corriente con la institución de aquellos que no la tienen. Si bien respecto de los primeros no se señala expresamente, se puede deducir de la regulación indicada que, en relación con ellos, se ha de cumplir, respecto de su identificación, lo dispuesto en el Capítulo 2-2 de la Recopilación de Normas de la SBIF, referido a cuentas corrientes bancarias y cheques. Ahora, en relación con aquellos clientes que no mantienen una cuenta corriente con la institución, pero que habitual u ocasionalmente realicen operaciones con ella, se recomienda al menos aplicar las exigencias establecidas al respecto en el Capítulo 2-2 indicado ${ }^{85}$.

Por su parte, la Superintendencia de Valores y Seguros, si bien establece el deber de las entidades sometidas a su fiscalización de "...adoptar como una politica rutinaria y propia de su forma de operar un adecuado conocimiento de sus clientes, de las actividades generadoras de los recursos utilizados en sus transacciones y de las características más relevantes de las operaciones que estos realizan..." solo se refiere al contenido preciso de dicha obligación cuando se esté en presencia de operaciones en efectivo (en moneda de curso legal o moneda extranjera) o instrumentos negociables al portador sobre 450 Unidades de Fomento o ante una operación sospechosa de lavado de activos ${ }^{86}$.

${ }^{83}$ Circular $\mathrm{N}^{\circ} 3$, sección 2 A., de la Superintendencia de Casinos de Juego.

${ }^{84}$ En este sentido, se señala que si el cliente se niega a realizar esta declaración, ello no impedirá la operación "...pero deberá considerarse como una importante señal de alerta de operación sospechosa y, consecuentemente, considerar su reporte a la UAF” (Circular de la UAF No 0018, sección No 1, de 11 de mayo de 2007, dirigida a casas de cambio, empresas de transferencia de dinero y empresas de transporte de valores y dinero).

85 Capítulo 1-14, sección II. 2., de la Recopilación de Normas de la Superintendencia de Bancos e Instituciones Financieras. Sin embargo, en este caso se permite, considerando la naturaleza, características y nivel de riesgo de los productos y servicios que contraten con el banco, omitir ciertos requisitos como, por ejemplo, la exigencia de una fotografía del cliente y la impresión digital. En cualquier caso, tratándose de personas jurídicas, “... deberá demostrarse la existencia de la sociedad, mediante copias de las escrituras e inscripciones correspondientes, la identificación de los propietarios de la empresa -accionistas o socios-y de las personas que componen su nivel directivo y los cargos que ocupan, de acuerdo al tipo de sociedad de que se trate. Asimismo, deberán identificarse sus representantes legales, las actividades que desarrolla la empresa, su dirección y números telefónicos".

${ }^{86}$ Ello resulta de la lectura de la Circular No 1809 , secciones No 3 y 4, de la SVS, De conformidad con lo dispuesto en la sección $4^{\circ}$ de dicha normativa, la "información mínima” que se requiere en estos casos es: a) Naturaleza de la operación y copia de los documentos o antecedentes que la respaldan; b) Nombre, apellidos, RUT o su equivalente para los extranjeros no residentes, nacionalidad, profesión, giro, domicilio, número telefónico y correo electrónico del inversionista, cliente o parte de la operación, 
Finalmente, la reciente Circular No 1480, sección No 3, de la Superintendencia de AFP, en relación con el contenido de este deber, establece como obligación de las AFP la de identificar "...en especial a todo aquel que realice operaciones de depósito y giro de carácter voluntario", sin indicar expresamente la documentación que se habrá de requerir al respecto ${ }^{87}$. Sin embargo, en lo tocante a los afiliados independientes, la Circular señala que "...las AFP deberán solicitarles antecedentes que acrediten la existencia de la sociedad o herramienta legal a través de la cual desarrollan su giro. Si la condición de independiente de un afiliado proviene del desarrollo de un giro de una persona jurídica, además de la identificación de los propietarios, accionistas o socios mayoritarios de la misma, los representantes legales, las actividades que desarrolla, el domicilio y números de teléfono"88.

Es importante destacar que la normativa antiblanqueo, en el contexto del deber de identificación indicado, adopta una postura que insta a aplicar medidas diferenciadas en relación con el riesgo de lavado de activos que el(los) cliente(s) o la(s) operación(es) puede(n) significar para los sujetos obligados. Mientras mayor sea el riesgo que pueden representar, más exigentes habrán de ser las medidas $K Y C$ que se establezcan ${ }^{89}$. Así, por ejemplo, en el caso de los clientes calificados como persona(s) de influencia a nivel

copia del mandato si opera para un tercero o, en ausencia de tal contrato, constancia de actuar para un tercero y la completa identificación de aquel, con inclusión de los datos suficientes para poder contactarle. Para las personas jurídicas, deberá dejarse copia de sus antecedentes legales y la individualización de sus representantes; c) Aquella documentación que permita determinar la extensión de relaciones que una empresa pueda tener con otras, esto es, determinar si es parte de un holding empresarial o grupo de empresas con un determinado objetivo. Y, por tanto, aquella que permita la determinación de los miembros del grupo empresarial; y, d) Origen inmediato de los recursos con los que se efectúa la transacción, respecto de aquellas operaciones que superen las 450 Unidades de Fomento. Además se deben adoptar medidas para lograr un rápido acceso a esta información, a fin de atender a los requerimientos que se efectúen en relación a operaciones y personas. En el caso que por cualquier circunstancia los antecedentes de un cliente hubieren sido obtenidos por una tercera entidad distinta a la entidad financiera, esta última deberá asegurarse que tales antecedentes le sean enviados en un plazo no mayor a tres (3) días hábiles.

${ }^{87}$ Ahora, de la lectura de la sección de la Circular indicada, se colige que se deberán obtener antecedentes, al menos, acerca de la actividad del afiliado (tipo y dimensión), origen de los fondos que deposita y país de origen de los mismos.

${ }^{88}$ Cabe hacer presente que, en virtud de lo dispuesto en la "Disposición transitoria" de la circular indicada "Para los efectos de dar cumplimiento a la obligación de identificación de afiliados con los requisitos minimos exigidos en esta Circular y que a la fecha tienen efectuados depósitos voluntarios, las AFP tendrán el plazo de un año desde la entrada en vigencia de la presente normativa. Lo anterior sin perjuicio de solicitarlos cuando el afiliado efectúe alguna operación". En este contexto, hacemos presente que, de acuerdo con la fecha de entrada en vigencia de la circular (1 de enero de 2008), esta obligación se encontrará operativa a partir del 1 de enero de 2009.

89 Esta tendencia se ha visto reflejada en la formulación, por parte del GAFI, de una guía orientada a la elaboración de políticas de prevención basadas en el riesgo de blanqueo. En este sentido véase GAFI (2007). La aplicación adecuada de una política de conocimiento de los clientes orientada al riesgo de blanqueo es fundamental para afrontar con éxito un programa de prevención de lavado de activos SLOAN (2005) p. 22. Así, esta forma de enfrentar las medidas de prevención de blanqueo de capitales persigue la eficiencia del sistema, reduciendo sus costos, enfocando la aplicación de las mismas en aquellos casos que representan un verdadero riesgo de blanqueo Ross y HANNAN (2007) p. 107. 
internacional o persona(s) politicamente expuesta(s) (o PEPS $)^{90}$, suele exigirse la aprobación de la alta administración de la entidad para su vinculación a la misma ${ }^{91}$. También se establece que se han de adoptar medidas KYC reforzadas respecto de la banca corresponsal ${ }^{92}$, las transferencias electrónicas de fondos ${ }^{93}$ y las operaciones que se realicen o

${ }^{90} \mathrm{La}$ Circular $\mathrm{N}^{\circ} 1809$, sección $\mathrm{N}^{\circ}$ 2, de la SVS dispone que dentro de esta categoría de clientes se encontrarían "...los individuos que desempeñan o han desempeñado funciones públicas destacadas en un país extranjero, considerando, entre otros, a los jefes de Estado o de gobierno, líderes políticos, funcionarios gubernamentales, judiciales o militares de alta jerarquía, altos ejecutivos de empresas estatales o funcionarios o miembros importantes de partidos politicos". La misma noción de "persona políticamente expuesta" o PEP, se encuentra recogida en las Circulares de la UAF indicadas en la nota No 76 de este estudio, particularmente en su sección 1., así como en la Circular No 3, sección 2 A., de la Superintendencia de Casinos de Juego, y en la reciente Circular No 1480, sección No 3, de la Superintendencia de AFP Cabe hacer presente que el Capítulo 1-14 de la Recopilación de Normas de la SBIF no contempla una definición de PEP.

${ }^{91}$ Esta medida aparece consignada en la Circular No 1809, sección No 2, de la SVS, en las Circulares de la UAF citadas en la nota 76 de este trabajo, particularmente, en la sección dedicada al "conocimiento del cliente" de las mismas, así como en el Capítulo 1-14 de la Recopilación de Normas de la SBIF, particularmente, en su sección II. 2 y en la reciente Circular No 1480, sección No 3, de la Superintendencia de AFP. En este último caso, tanto la afiliación de PEPS como la realización por parte de estos de depósitos o giros de carácter voluntario, deberá ser puesto en conocimiento de la alta dirección o administración de la respectiva AFP.

92 Así, el Capítulo 1-14 de la Recopilación de Normas de la SBIF, en su sección II. 3., señala que, en este caso, las instituciones financieras, además de aplicar los deberes de identificación ya indicados, “... deberán: i) reunir información suficiente sobre los bancos con los cuales mantengan cualquier tipo de relación que les permita comprender cabalmente la naturaleza de los negocios que estos desarrollan y verificar la reputación y la calidad de su supervisión; ii) tomar conocimiento de los controles implementados para detectar operaciones de lavado de activos y financiamiento del terrorismo; $y$, iii) documentar las respectivas responsabilidades de cada institución, cuando sea del caso".

${ }^{93}$ En este sentido, la Circular de la UAF No 0010, de 5 de septiembre de 2006 (dirigida a todos los sujetos obligados), establece para quienes realicen o reciban transferencias electrónicas de fondos, ya sea transfronterizas o nacionales, la obligación de incorporar información precisa y significativa del remitente, sobre las transferencias de fondos y los mensajes relacionados enviados. Se señala que la información deberá permanecer con la transferencia o mensaje relacionado a través de la cadena de pago. Para todas las transferencias electrónicas de fondos, las instituciones remitentes deberán obtener y conservar por un plazo mínimo de cinco años, al menos la siguiente información relativa al ordenante de la transferencia, verificando, además, que esta sea exacta: a) monto y fecha de la transferencia; b) nombre del ordenante; c) número de cédula de identidad, para chilenos o residentes, o de pasaporte o similar documento de identificación para extranjeros no residentes; d) número de cuenta del ordenante (o, en su defecto, el número de referencia asignado a la operación). e) domicilio del ordenante. Asimismo, las instituciones que reciben trasferencias electrónicas de fondos deberán adoptar procedimientos eficaces basados en el riesgo para aislar y gestionar las transferencias que no vengan acompañadas de información completa sobre el ordenante. La falta de la información completa del ordenante puede ser considerada como un factor al evaluar si una transferencia electrónica o las transacciones relacionadas con ella son sospechosas y, en consecuencia, deban ser reportadas a la Unidad de Análisis Financiero. Cuando la situación lo amerite, la institución receptora de la transferencia electrónica deberá considerar restringir o incluso terminar su relación de negocios con la institución remisora que incumple con estas prácticas. Asimismo, deberán abstenerse de procesar transferencias cuando el ordenante que la solicita no entrega la información mínima más arriba mencionada. Lo anterior no será necesario en los siguientes tipos de pagos: 1. Cualquier transferencia que se derive de una transacción realizada utilizando una tarjeta de crédito o débito, siempre que el número de dicha tarjeta acompañe a todas las transferencias derivadas de la transacción. Sin embargo, si las tarjetas de crédito o débito se utilizan como sistema de pago para efectuar una transferencia de dinero, esta instrucción es aplicable, y debe incluirse la información necesaria en el o los mensajes; y, 2. Las transferencias y liquida- 
relaciones comerciales que se entablen con personas naturales o jurídicas, incluidas las empresas e instituciones financieras, de países donde no se apliquen la recomendaciones del GAFI o no se las respete suficientemente ${ }^{94}$.

La información recabada respecto de los clientes y sus actividades debe ser verificada por el sujeto obligado ${ }^{95}$. Además debe mantenerse actualizada ${ }^{96}$ y en poder de estos, al menos, por un plazo de 5 años, contados desde la fecha de la última operación

ciones entre instituciones financieras cuando tanto el ordenante como el beneficiario son instituciones financieras que actúan en su propio nombre. Por su parte, el Capítulo 1-14, sección No II. 2, de la Recopilación de Normas de la SBIF, señala que, "Especial atención se deberá tener en el caso de transferencias de fondos en cuanto a identificar al ordenante y al beneficiario".

94 En su oportunidad apuntamos que existían ciertas zonas geográficas cuya regulación, o más bien, la falta de ella, podía eventualmente, posibilitar operaciones de lavado de activos. En este sentido véase la nota $\mathrm{N}^{\circ} 24$ de este trabajo. Respecto de este tema se debe estar a lo dispuesto en la Circular de la UAF No 0009, de 23 de agosto de 2006 (dirigida a todos los sujetos obligados). Conforme a esta, cuando las operaciones que realicen los sujetos obligados y las relaciones comerciales que entablen con personas naturales o jurídicas, incluidas las empresas e instituciones financieras, de países donde no se aplican las Recomendaciones del GAFI o no se las aplica suficientemente, “...no tengan una justificación jurídica o económica aparente, deberá examinarse su trasfondo y fines, en la mayor medida posible (conocimiento del cliente reforzado) plasmándose los resultados por escrito, los que deberán ser puestos a disposición de la Unidad de Análisis Financiero. Para estos efectos se deberá considerar a los catalogados como "países o territorios no cooperantes" por el GAFI y a los definidos como "paraisos fiscales" por la Organización de Cooperación y Desarrollo Económico (OCDE) los que se encuentran incluidos en el Decreto Supremo 628 de 2003 del Ministerio de Hacienda, que se dictó de acuerdo a lo estipulado la Ley 19.840, y que se actualiza en base a la lista que periódicamente elabora la OCDE". Tanto la lista de países o territorios no cooperantes del GAFI, como la nómina de los paraísos fiscales incluida en el anteriormente mencionado decreto supremo se contienen en la Circular citada y se encuentran disponibles en el sitio web de la UAF, debiendo cada institución revisarla periódicamente. Hacemos presente que hoy la lista de países no cooperantes se encuentra vacía. Ello considerando que el último país que aparecía en ella, Myanmar, ha sido removido de la misma, mediante resolución adoptada en el pleno del GAFI, realizado en Vancouver entre el 10 y el 13 de octubre de 2006. Sobre el efecto que puede traer para los países formar parte de nóminas de este tipo, véase MASCIANDARO (2005) Pp. 17-30.

95 El Capítulo 1-14, sección II. 2, de la Recopilación de Normas de la SBIF, dispone que se “...deberá verificar y asegurarse, por los medios que estime adecuados, que la información sobre la identificación entregada por clientes corresponda a la realidad". Este deber se recoge, en similares términos en la reciente Circular No 1480, sección No 3 de la Superintendencia de AFP y en las Circulares de la UAF indicadas en la nota No 76 de este trabajo, salvo el caso de la Circular $N^{\circ}$ 0018, de 11 de mayo de 2007 (dirigida a las casas de cambio, empresas de transferencia de dinero y empresas de transporte de valores y dinero), que no se refiere expresamente a este punto. Cabe hacer presente que esta obligación no se encuentra consagrada expresamente en las Circulares No 1809 de la SVS y No 3 de la Superintendencia de Casinos de Juego.

96 En este sentido, las Circulares de la UAF indicadas en la nota 76 de este trabajo, en su sección № 1 , disponen que se "...deberá mantener actualizados los antecedentes de sus clientes en el curso de su relación contractual, de modo de asegurarse que los datos de identificación y financieros corresponden en tiempo y forma a los verdaderos..." . Además, se debe “...prevenir al cliente de su obligación de actualizar, al menos anualmente, la información que varie, suministrando los documentos de respaldo correspondientes". Lo anterior no aparece consignado en la Circular $\mathrm{N}^{\circ}$ 0018, de 11 de mayo de 2007 (dirigida a las casas de cambio, empresas de transferencia de dinero y empresas de transporte de valores y dinero). Sin embargo, esta obligación se encuentra recogida, en similares términos, en el Capítulo 1-14, sección No II. 2, de la Recopilación Actualizada de Normas de la SBIF, y en la reciente Circular No 1480, sección No 3, de la Superintendencia de AFP. Cabe hacer presente que esta obligación no se encuentra consagrada expresamente en las Circulares No 1809 de la SVS y No 3 de la Superintendencia de Casinos de Juego. 
realizada con el cliente. Esta información podrá ser revisada o requerida por la UAF en cualquier momento, de conformidad con las disposiciones de la Ley $19.913^{97}$.

Respecto de la eficacia de una política $K Y C$, se debe señalar que esta es fundamental para afrontar con éxito la primera etapa del lavado de activos, impidiendo que capitales ilícitos ingresen al circuito económico. Sin embargo, para el logro cabal de los objetivos de prevención, las políticas de conocimiento del cliente deben posibilitar la detección de operaciones sospechosas también después de que los dineros ilícitos han ingresado al sistema, para lo que el monitoreo de las operaciones de los clientes, resulta fundamental ${ }^{98}$. Para el logro de este objetivo, los sujetos obligados, con los antecedentes obtenidos respecto de sus clientes, debidamente actualizados, deben "...elaborar perfiles de clientes, que permitan determinar en forma aproximada, el volumen y tipo de operaciones que harán estos en lo futuro"99. En este contexto, se establece que se habrá de contemplar procedimientos que deberán considerar el nivel de riesgo que el cliente representa para la institución ${ }^{100 "}$.

Estrechamente relacionada con el deber de reportar las operaciones sospechosas a la Unidad de Análisis Financiero, según lo dispone el artículo 3 de la Ley 19.913, se establece como segunda medida adicional de prevención, la de diseñar e implementar

${ }^{97}$ En este caso, se trata de una obligación que opera sin perjuicio de aquella consagrada en el artículo 5 de la Ley 19.913, que ya hemos revisado. Ello se indica expresamente en las circulares de la UAF señaladas en la nota No 76 de este trabajo. Este deber también se recoge en la reciente Circular No 1480, sección No 3, de la Superintendencia de AFP y en la Circular No 3, sección 2 A, de la Superintendencia de Casinos de Juego. Cabe hacer presente que el Capítulo 1-14 de la Recopilación de Normas de la SBIF ni la Circular No 1809 de la SVS, también se refieren expresamente a este punto.

98 RiCHARDS (1998) p. 88.

99 Capítulo 1-14, sección II. 2., de la Recopilación de Normas de las SBIF. La existencia de "perfiles de operación de clientes" también se deduce de lo dispuesto en la Circular No 1809, sección No 2, de la SVS, que señala que "Asimismo, deben procurar obtener información que les permita explicar o entender la realización de transacciones que no están de acuerdo a los antecedentes que se disponen del mismo cliente, o de aquellas que por su volumen, reiteración, contraparte o monto parezcan inusuales". Esta disposición se encuentra consagrada, en similares términos, en las circulares de la UAF, indicadas en la nota $\mathrm{N}^{\circ} 76$ de este trabajo. Ello también se desprende de la lectura de la reciente Circular No 1480, sección No 3, de la Superintendencia de AFP, dispone que los antecedentes de los afiliados han de estar actualizados, "con el objeto que permita asegurar que las operaciones de carácter voluntario, como depósitos y giros voluntarios, que realizan estos afiliados resulten ser coherentes con el tipo y dimensión de sus actividades. Entre los factores a considerar deben incluirse, los antecedentes de identificación personal, los perfiles de riesgo de la actividad que declare realizar, monto y origen de los fondos que está depositando, y país de origen de estos como la periodicidad de los giros". Hacemos presente que, lo anterior, no aparece consignado en la Circular $N^{\circ} 0018$, de 11 de mayo de 2007 (dirigida a las casas de cambio, empresas de transferencia de dinero y empresas de transporte de valores y dinero) ni en la Circular $\mathrm{N}^{\circ} 3$ de la Superintendencia de Casinos de Juego.

100 El Capítulo 1-14, secciones II.2 y II.3., de la Recopilación de Normas de la SBIF, además señala que “... Para los clientes que estén dentro de la categoría de politicamente expuestos a nivel internacional o para personas que, de acuerdo con su perfil, pudieran estar expuestas a ser utilizadas para el lavado de activos, corresponderá desarrollar un sistema especial de seguimiento de sus operaciones". En este contexto, la Circular No 3, sección 2.A., de la Superintendencia de Casinos de Juego, dispone que se deberá prestar especial atención a los clientes que desempeñan o han desempeñado funciones públicas destacadas en un país extranjero. Por su parte, la Circular No 1809, sección No 2, de la SVS, señala que, mientras se mantengan las relaciones comerciales con esta categoría de clientes, las entidades deberán realizar una supervisión intensificada de las mismas. 
“...los mecanismos necesarios para la detección de operaciones sospechosas". Por su parte, "...para el caso de detectarse operaciones sospechosas deben establecerse procedimientos especificos que garanticen la confidencialidad de la información y los procedimientos internos que aseguren los minimos plazos para el reporte de estas a la UAF"101.

Otra medida antiblanqueo diseñada, es la de seleccionar adecuadamente ${ }^{102}$ y capacitar, en forma permanente, al personal de los sujetos obligados. En este sentido, la UAF ha establecido que se "... debe contemplar el desarrollo y ejecución de programas de capacitación e instrucción permanentes a sus empleados, actividad a la que estos deberán asistir a lo menos una vez al año". En cuanto al contenido de dichos programas, se ha señalado que este debe incluir "... a lo menos, los conceptos de lavado o blanqueo de activos y sus consecuencias, la normativa que regula la materia y sus sanciones tanto administrativas como penales así como, también, las señales de alerta y procedimientos frente a una operación de carácter sospechosa" 103 .

101 Ello sobre la base de las "señales de alerta" formuladas por la UAF. En este sentido, véase la nota $\mathrm{N}^{\circ}$ 58 de este trabajo. Así lo disponen las circulares de la UAF indicadas en la nota $\mathrm{N}^{\circ} 76$ de este estudio. Esta misma obligación se formula, en similares términos en la Circular $\mathrm{N}^{\circ} 1809$, sección $\mathrm{N}^{\circ} 2$, de la Superintendencia de Valores y Seguros y en las Circulares $N^{\circ} 3$, sección $N^{\circ} 2$. B., de la Superintendencia de Casinos de Juego y $\mathrm{N}^{\circ} 1480$, sección $\mathrm{N}^{\circ} 2$, de la Superintendencia de AFP Por su parte, el Capítulo 1-14, sección $N^{\circ}$ II. 6., de la Recopilación de Normas de la SBIF establece en este ámbito, que "Las entidades deben contar con las herramientas tecnológicas adecuadas, que le permitan desarrollar sistemas de alertas, con el propósito de identificar y detectar operaciones inusuales. Dichos instrumentos deberán ser capaces de monitorear todas las transacciones realizadas por sus clientes a través de los diversos productos, prestando especial atención a aquellas que se efectúen con dinero en efectivo. Los parámetros de detección de operaciones inusuales considerarán en su aplicación el riesgo de clientes y/o productos. Asimismo, deberán desarrollar y proveer a las instancias encargadas de ejecutar los servicios a los clientes, de una lista de "señales de alerta", que les sirvan para detectar operaciones inusuales o conocer operaciones sobre las cuales deben tener especial prudencia. (...) Todos los análisis efectuados de estas operaciones deben quedar debidamente documentados. Identificada una operación sospechosa... el banco está obligado a reportar dicha operación a la Unidad de Análisis Financiero".

102 Este deber se encuentra establecido expresamente en las Circulares $\mathrm{N}^{\circ} 3$, sección $\mathrm{N}^{\circ} 2 \mathrm{D}$., de la Superintendencia de Casinos de Juego; No 1809, sección $N^{\circ} 7$, de la Superintendencia de Valores y Seguros; y en el Capítulo 1-14, sección II. 7, de la Recopilación de Normas de la SBIF, que establece en este ámbito, que "Los bancos deben contar con politicas y normas de selección de personal y de conducta de este en relación con clientes, con el objeto de prevenir la ocurrencia de operaciones de lavado de activos y financiamiento del terrorismo".

${ }^{103}$ Ello de acuerdo con lo establecido en las circulares de la Unidad de Análisis Financiero indicadas en la nota $\mathrm{N}^{\circ} 76$ de este trabajo, así como en la Circular $\mathrm{N}^{\circ} 3$, sección 2 D., de la Superintendencia de Casinos de Juego y en la $\mathrm{N}^{\circ} 1480$, sección 4, de la Superintendencia de AFP En este sentido, la Circular No 1809, sección $\mathrm{N}^{\circ} 7$, de la Superintendencia de Valores y Seguros, señala que “...dicha capacitación deberá ser especialmente hecha a funcionarios que se relacionan directamente con clientes, operadores de mesa de dinero, de rueda, personal de auditoría y aquellos encargados especialmente del seguimiento de operaciones de los clientes que pudieren ser hechas para lavar activos y/o financiar el terrorismo". Por su parte, el Capítulo 1-14, sección $\mathrm{N}^{\circ}$ II. 7, de la Recopilación de Normas de la SBIF establece que "Estos programas deberán comprender a todo el personal del banco, incluido el de sus filiales y sociedades de apoyo al giro cuando corresponda, y deberán ser periódicos y diferenciados según se trate de personal nuevo, de la función de cumplimiento, del área atiende público en forma directa". 
También se contempla, como deber antiblanqueo, el de elaborar manuales de procedimiento frente a una operación sospechosa ${ }^{104}$ y códigos de conducta aplicables al personal de los sujetos obligados ${ }^{105}$.

Finalmente, se establece como deber de prevención de lavado de activos, el diseño y aplicación de programas de auditoría interna, destinados a evaluar la eficacia del sistema de prevención implementado en la entidad correspondiente ${ }^{106}$.

Cabe hacer presente que el sistema de prevención de blanqueo de capitales establecido por cada sujeto obligado, en concordancia con la normativa indicada, habrá de contar con el compromiso de la dirección de la entidad correspondiente ${ }^{107}$. Ello se refleja en la participación de sus miembros en el Comité de Prevención de Lavado de Activos y Financiamiento del Terrorismo ${ }^{108}$, así como en la aprobación y evaluación

${ }^{104}$ Respecto de este deber, la UAF ha señalado que el manual “... deberá constar por escrito y ser de conocimiento de todo el personal de la respectiva empresa. (...) Asimismo, es obligatorio que el referido manual sea actualizado periódicamente, tanto respecto de las operaciones que incorporen a su cartera de productos como de las nuevas señales de alerta y eventuales tipologías que se entreguen". Ello de acuerdo con lo establecido en las Circulares de la UAF indicadas en la nota $\mathrm{N}^{\circ} 76$ de este trabajo, así como en la Circular $\mathrm{N}^{\circ} 3$, sección 2., de la Superintendencia de Casinos de Juego y en la $\mathrm{N}^{\circ}$ 1480, sección 4, de la Superintendencia de AFP. A este respecto, la Circular No 1809, sección $N^{\circ}$ 5, de la Superintendencia de Valores y Seguros, indica que "Las entidades deberán contar con un manual de procedimientos, relativo a normas y pautas que la entidad debe aplicar para prevenir, detectar y evitar la facilitación y realización de operaciones de lavado de dinero o de financiamiento del terrorismo dentro de su giro, para conocer cabalmente a sus clientes e inversionistas y las actividades que realizan, particularmente cuando estas difieran de sus actividades conocidas". El Capítulo 1-14, sección $\mathrm{N}^{\circ}$ II. 3., de la Recopilación de Normas de la SBIF establece, en su número 3 este mismo deber.

105 En este contexto, la Circular No 1809, sección $N^{\circ} 5$, de la Superintendencia de Valores y Seguros, establece que "Las entidades deberán contar con un código de conducta del personal, que podrá formar parte del manual de procedimientos... el cual contendrá los principios que la institución determine respecto de las relaciones y operaciones que deben efectuarse con los inversionistas, clientes o partes de la operación, de manera que se asegure una conducta dentro de un estricto marco ético que evite un comportamiento que permita o facilite la realización de operaciones de lavado de dinero". Por su parte, el Capítulo 1-14, sección $\mathrm{N}^{\circ}$ II. 7, de la Recopilación de Normas de la SBIF dispone que las instituciones financieras “...deben disponer de reglas de conducta contenidas en un código, que orienten la actuación de cada uno de sus funcionarios para el adecuado desarrollo del sistema de prevención adoptado, y prevenir y resolver conflictos de intereses que pudieran surgir con sus clientes". No se contemplan medidas de este tipo en las Circulares de la UAF indicadas en la nota $\mathrm{N}^{\circ} 76$ de este trabajo, ni en las Circulares $\mathrm{N}^{\circ} 1809$ de la Superintendencia de Valores y Seguros y $\mathrm{N}^{\circ}$ 1480 de la Superintendencia de AFP.

106 Ello de acuerdo con lo establecido en las circulares de la UAF indicadas en la nota $\mathrm{N}^{\circ} 76$ del presente trabajo y en las Circulares $\mathrm{N}^{\circ}$ 3, sección 2. E, de la Superintendencia de Casinos de Juego; y, $\mathrm{N}^{\circ} 1480$, sección $\mathrm{N}^{\circ}$ 4, de la Superintendencia de AFP. Por su parte, el Capítulo 1-14, sección II. 8, de la Recopilación de Normas de la SBIF también establece este deber. Respecto de la auditoría de los sistemas de prevención del blanqueo de capitales, se recomienda la formulación de auditorías anuales e independientes. SLOAN (2005) pp. 20-23.

107 El compromiso de los sujetos obligados, a nivel de su dirección, en relación con las políticas de prevención de lavado de activos, es fundamental para el éxito de las mismas. En este sentido, SLOAN sostiene que, justamente, la falta de compromiso en este ámbito es una de las causas que explicarían las fallas que se detectan en estos programas. Arguye que esta circunstancia estaría dada, muchas veces, por la falta de comprensión a nivel directivo del propósito que subyace al establecimiento de medidas antiblanqueo por las autoridades. SLOAN (2005) p. 21.

108 En este contexto, el Capítulo 1-14, sección II. 5., de la Recopilación de Normas de la SBIF dispone que "Dependiendo de su tamaño, la institución deberá constituir un Comité de Prevención de Lavado de Activos y Financiamiento del Terrorismo. Es deseable que este Comité esté integrado por a lo menos un director 
periódica de los principales aspectos de las políticas diseñadas e implementadas por la entidad $^{109}$. Por su parte, estas serán controladas periódicamente por las autoridades supervisoras que correspondan, en su caso ${ }^{110}$.

\section{COMENTARIOS FINALES}

El blanqueo de capitales se desarrolla a través de un proceso, más o menos complejo, y sus principales características son: su gran volumen, suele estar a cargo de organizaciones profesionales y es de carácter internacional.

La lucha contra este fenómeno ha sido objeto de gran preocupación por parte de las autoridades de los Estados, fundamentalmente, a partir de 1980, elaborándose nume-

(no exigible para sucursal de entidad extranjera), el gerente general, a lo menos un gerente de área, el fiscal y el Oficial de Cumplimiento. Entre sus funciones estará la de planificar y coordinar las actividades de cumplimiento de las politicas y procedimientos sobre las materias definidas por la entidad (...) Además, deberá tomar conocimiento de la labor desarrollada y operaciones analizadas por el Oficial de Cumplimiento, como también, de decidir sobre mejoras a las medidas de control que este proponga". La creación de un organismo de este tipo también está contemplada en la Circular No 3, sección 2 C., de la Superintendencia de Casinos de Juego, que señala que este "... estará conformado por la totalidad de los integrantes del Directorio de la sociedad que explota el casino de juego, o por el o los administradores en los casos de sociedades que no cuenten con un directorio, asi como, en ambos casos, por quienes desempeñen los cargos de Gerente General de dicha sociedad y de Oficial de Cumplimiento de esta". No se contemplan expresamente medidas de este tipo en las Circulares de la UAF indicadas en la nota $\mathrm{N}^{\circ} 76$ de este trabajo, ni en las Circulares $\mathrm{N}^{\circ} 1809$ de la Superintendencia de Valores y Seguros y $N^{\circ} 1480$ de la Superintendencia de AFP.

${ }^{109}$ La Circular No 1809, sección $N^{\circ} 8$, de la SVS, establece en este ámbito que "El directorio o administración de la entidad deberá aprobar el manual de procedimientos y código de conducta, así como evaluar al menos una vez dentro del año calendario, las políticas y procedimientos establecidos en el mismo, su cumplimiento y efectividad". Por su parte, el Capítulo 1-14, sección II. 1, de la Recopilación de Normas de la SBIF señala que "El Directorio deberá aprobar el sistema de prevención de lavado de activos y financiamiento del terrorismo... A su vez, deberá recibir información periódica sobre las operaciones analizadas, las acciones realizadas sobre ellas, aquellas informadas a la Unidad de Análisis Financiero y también sobre el cumplimiento de las politicas y procedimientos internos". Este deber está establecido, en similares términos, en la Circular $\mathrm{N}^{\circ} 3$, sección 2. E. y 3., de la Superintendencia de Casinos de Juego. No se contemplan expresamente medidas de este tipo en las Circulares de la UAF indicadas en la nota $\mathrm{N}^{\circ} 76$ de este trabajo, ni en la Circular $\mathrm{N}^{\circ}$ 1480 de la Superintendencia de AFP.

110 Así, la Circular de la UAF No 1480, sección 4., de la Superintendencia de AFP., establece que " $L a$ suficiencia y eficacia de las politicas y procedimiento sobre prevención de lavado de activos formarán parte del proceso de supervisión, control y evaluación por parte de la Superintendencia de Administradoras de Fondos de Pensiones". En el caso de los casinos de juego, dicha evaluación, según lo dispone la Circular No 3, sección 4, de la Superintendencia de Casinos de Juego, será efectuada por dicho organismo supervisor actuando, en conjunto, con la UAF. En el caso de la Superintendencia de Valores y Seguros, según se dispone en la Circular No 1809 , sección $\mathrm{N}^{\circ}$ 8, las actas de Directorio de las entidades fiscalizadas en que consten las decisiones adoptadas en materia de prevención de blanqueo de capitales, observaciones respecto de la efectividad del manual de procedimiento, código de conducta y sistema implementado para la detección de operaciones de lavado de activos y/o financiamiento del terrorismo podrán ser examinadas por la SVS. Por su parte, según lo dispone el Capítulo 1-14, sección $\mathrm{N}^{\circ} 3$, de la Recopilación de Normas de la Superintendencia de Bancos e Instituciones Financieras, se ha incorporado en el proceso de supervisión evaluación y clasificación de las entidades financieras, la suficiencia y eficacia de las políticas y procedimientos sobre prevención de lavado de activos y financiamiento del terrorismo. En este sentido, véase el Capítulo 1-13 de la Recopilación de Normas de la Superintendencia de Bancos e Instituciones Financieras, disponible en www.sbif.cl (última visita realizada al sitio web, 4.4.2008). 
rosos instrumentos que apuntan a su erradicación de la sociedad. Producto de las características que reviste el lavado de activos, se ha entendido este debe combatirse bajo un doble enfoque: utilizando un sistema represivo y uno preventivo. Este último, tiene como misión establecer medidas, aplicables a una serie de sujetos, principalmente del sistema financiero, a fin de evitar que se produzca el delito de blanqueo de capitales.

En nuestro país, este tipo de medidas se contiene, fundamentalmente, en la Ley $\mathrm{N}^{\circ}$ 19.913, que crea la Unidad de Análisis Financiero y modifica diversas disposiciones en materia de lavado y blanqueo de activos, publicada en el Diario Oficial con fecha 18 de diciembre de 2003. De acuerdo con esta Ley, los sujetos obligados por la misma deben: (a) informar las operaciones sospechosas de lavado de activos a la Unidad de Análisis Financiero; (b) proporcionar a dicho servicio los antecedentes que, con ocasión de la revisión de una operación sospechosa detectada por este en el ejercicio de sus atribuciones, resulten necesarios y conducentes para desarrollar o completar el análisis de dicha operación o bien a efectos de compartir información con sus similares en el extranjero; y, (c) mantener registros especiales por el plazo mínimo de cinco años, en informar a la Unidad de Análisis Financiero cuando esta lo requiera, de toda operación en efectivo superior a cuatrocientas cincuenta unidades de fomento o su equivalente en otras monedas.

Sin embargo, nuestro sistema de prevención de lavado de activos no termina aquí. La normativa apuntada se ve complementada por aquella de carácter sectorial, emanada, por ejemplo, de organismos como la Superintendencia de Valores y Seguros, la de Bancos e Instituciones Financieras, la de Casinos de Juego y la de Administradoras de Fondos de Pensiones. A lo anterior habrá que agregar la actividad desplegada en este ámbito por la Unidad de Análisis Financiero. La mayoría de estos instrumentos viene a aclarar ciertos aspectos en relación con la aplicación de las disposiciones contenidas en la Ley 19.913 que hemos examinado. Sin embargo, esta regulación también incorpora nuevos deberes, que vienen a reforzar aquellos establecidos por la Ley.

De conformidad con estos instrumentos, se establecen, como medidas de prevención adicionales, en términos generales, las siguientes: (a) el conocimiento de los clientes; (b) el diseño e implementación de los mecanismos necesarios para la detección de operaciones sospechosas; (c) la selección adecuada y capacitación, en forma permanente, del personal de los sujetos obligados; (d) la elaboración de manuales de procedimiento frente a una operación sospechosa y códigos de conducta aplicables al personal de los sujetos obligados; (e) el diseño y aplicación de programas de auditoría interna, destinados a evaluar la eficacia del sistema de prevención. Este último deberá contar con el compromiso de la dirección de la entidad correspondiente, lo que se refleja en la participación de sus miembros en el Comité de Prevención de Lavado de Activos y Financiamiento del Terrorismo, así como en la aprobación y evaluación periódica de los principales aspectos de las políticas diseñadas e implementadas en este ámbito. Por su parte, dichas políticas serán controladas periódicamente por las autoridades supervisoras que correspondan, en su caso.

La existencia de las medidas expuestas en el número anterior, de relevante contenido e incluso más numerosas que aquellas contempladas en la Ley 19.913, da cuenta de 
un sistema de prevención de lavado de activos que ha evolucionado notablemente durante los últimos años ${ }^{111}$. Creemos que, producto de la proliferación de regulación en este ámbito, será imposible, en un futuro cercano, entregar una visión general de dicho sistema. Los estudios doctrinarios que se realicen tendrán, seguramente, que enfocarse en las medidas de prevención establecidas, en forma particular, para cada uno de los sujetos obligados. Es por ello que aprovechamos la que puede ser, nuestra última oportunidad, para abordar esta tarea.

\section{BIBLIOGRAFÍA CITADA}

AlBA, Ricardo (2002): "Evolution of methods of money laundering in Latin America", Journal of Financial Crime vol. 10 no 2: pp. 137-140.

AleXAnder, Kern (2001): “The internacional Anti-Money Laundering Regime: The Role of the Financial Action Task Force", Journal of Money Laundering Control, vol. 3 no 3: pp. 231-238.

Álvarez, Daniel y Eguidazu, Fernando (1997): La prevención del blanqueo de capitales (Navarra, Aranzadi) 429 pp.

Álvarez, Daniel y Eguidazu, Fernando (2007): Manual de prevención del blanqueo de capitales (Madrid, Marcial Pons) 647 pp.

BLANCO, Isidoro (2002): El delito de blanqueo de capitales (Navarra, Aranzadi) 603 pp.

COMisión Interamericana para el CONTROl CONTRA El Abuso DE Drogas (CICAD) (2005): Reglamento Modelo sobre delitos de lavado de activos relacionados con el tráfico ilícito de drogas y otros delitos graves, Disponible en <http:// www.cicad.oas.org> [última visita al sitio web, 4.4.2008] $28 \mathrm{pp}$.

Comité De Supervisión Bancaria De Basilea (2001): Debida diligencia con la clientela de los bancos (Basilea, Banco de Pagos Internacionales) $28 \mathrm{pp}$.

DeL CID, Juan Miguel (2007): Blanqueo internacional de capitales. Cómo detectarlo y prevenirlo (Barcelona, Deusto) 319 pp.

Espín, Cristóbal (1991): "Desarrollo comunitario de normas tendentes a impedir la utilización del sistema financiero para el blanqueo de capitales", Revista de Derecho Bancario y Bursátil vol. 41: pp. 203-206.

FABIÁn, Eduardo (1998): El delito de blanqueo de capitales (Madrid, Colex) 521 pp.

FONDO MONETARIO INTERNACIONAL (2005): "Guía sobre los comités, grupos y clubes”, en Fichas Técnicas, Disponible en: <http://www.fatf-gafi.org> [Fecha de consulta: 4 de abril de 2008]

Grupo De ACCIÓn FinANCIERA InTERnACIONAL (2001): Recomendaciones especiales sobre la financiación del terrorismo, Disponible en: <http://www.fatf-gafi.org> [Fecha de consulta: 4 de abril de 2008]

111 Sin embargo, aún queda camino por recorrer para adaptarse a los estándares internacionales en esta materia. En este sentido, véase GAFISUD (2006), disponible en www.gafisud.org (última visita al sitio web, 4.4.2008). 
Grupo De ACción Financiera InTERnacional (2003): Las Cuarenta Recomendaciones del GAFI sobre blanqueo de capitales, Disponible en: <http://www.fatf-gafi.org> [Fecha de consulta: 4 de abril de 2008]

Grupo De ACCión FinANCiera InTERnacional (2004): Methodology for Assessing Compliance with the FATF 40 Recommendations and the FATF 9 Special Recommendations, Disponible en: <http://www.fatf-gafi.org> [Fecha de consulta: 4 de abril de 2008]

Grupo De Acción Financiera Internacional (2005): Tipologías de lavado de activos $y$ financiamiento del terrorismo 2004-2005, Disponible en: <http://www.fatfgafi.org> [Fecha de consulta: 4 de abril de 2008]

GRUPO DE ACCIÓN FINANCIERA INTERNACIONAL (2006): The misuse of coroporate vehicles, including trust and Company services providers. Disponible en: <http:// www.fatf-gafi.org> [Fecha de consulta: 4 de abril de 2008]

Grupo De ACCión FinANCIERA InTERnacional (2007): Guidance on the risk-based approach to combating money laundering and terrorist financing. High level Principles and Procedures, Disponible en: <http://www.fatf-gafi.org> [Fecha de consulta: 4 de abril de 2008]

GAFISUD (2004): Informe sobre tipologias de lavado de activos y financiamiento del terrorismo 2003-2004, Disponible en: <http://www.gafisud.org> [Fecha de consulta: 4 de abril de 2008]

GAFISUD (2005): Tipologías regionales GAFISUD-2005, Disponible en: <http:// www.gafisud.org > [Fecha de consulta: 4 de abril de 2008]

GAFISUD (2006): Informe de evaluación mutua sobre lavado de activos y financiamiento del terrorismo, Disponible en: <http://www.gafisud.org> [Fecha de consulta: 4 de abril de 2008]

GÓMEZ, Diego (1996): El delito de blanqueo de capitales en el derecho español (Barcelona, Cedecs) 116 pp.

Grupo EGMONT (2000): Fiu's in action. 100 cases from the Egmont Group, Disponible en: <http://www.egmontgroup.org> [Fecha de consulta: 4 de abril de 2008]

GuilléN, María José (1997): El secreto bancario y sus límites legales (Valencia, Tirant lo Blanch) 283 pp.

JOHNSON, Jackie y LiM, Desmond (2002): "Money Laundering: Has the Financial Action Task Force Made a Difference?", Journal of Financial Crime., vol. 10 no 1: pp. 7-22.

Kennedy, P. (2003): "Watching the Clothes Go Round: Combating the Effects of Money Laundering on Economic Development and International Trade", Currents International Trade Law Journal, vol. 12 no 1: pp. 143-144.

Lilley, Peter (2005): Dirty Dealing. The Untold Truth about Global Money Laundering, International Crime and Terrorism (Londres, Kogan Page) 220 pp.

Martorell, Daniel (2003): "Comentarios sobre la ley 19.913, que crea la Unidad de Análisis Financiero y sanciona el lavado de activos", Revista de Derecho Consejo de Defensa del Estado, vol. 10 no 2: pp. 123-146.

MASCIANDARO, Donato (2005): "False and Reluctant Friends? National Money Laundering Regulation, International Compliance and Non-Cooperative Countries, European Journal of Law and Economics, vol. 20 no 1: pp. 17-30. 
MATTHers, Chris (2004): Crime School: Money Laundering. True Crime Meets the World of Business and Finance (New York, Firefly Books) 240 pp.

Montalvo, Alicia (1995): "La prevención del blanqueo de capitales de origen ilícito", Información Comercial Española, 741, pp. 84-94.

Noble, Ronald y Columbic, Court (1998): "A New Anti-Crime Framework for the World: Merging the Objective and Subjective Models for Fighting Money Laundering", New York University Journal of International Law and Politics, vol. 30 no 1-2: pp. 80-144.

Palma, José Manuel (2000): Los delitos de blanqueo de capitales (Madrid, Edersa) 991 pp.

PRAMS, Claudio (2005): Estudio teórico práctico del delito de blanqueo de capitales en el derecho chileno con referencia al derecho comparado (Santiago de Chile, LexisNexis) $585 \mathrm{pp}$.

RICHARDS, James (1998): Transnacional Criminal Organizations, Cybercrime, and Money Laundering. A Handbook for Law Enforcement Officers, Auditors, and Financial Investigators (Florida, CRS Press) $297 \mathrm{pp}$.

ROLDÁN, José María (2001): "La cooperación en materia de lucha contra el blanqueo a nivel internacional: el GAFI (Grupo de Acción Financiera Internacional)", en: Prevención y Represión del Blanqueo de Capitales (Madrid, Consejo General del Poder Judicial) pp. 203-212.

Ross, Stuart y Hannan, Michelle (2007): "Money Laundering regulation and riskbased decision making”, Journal of Money Laundering Control, vol. $10 \mathrm{n}^{\circ}$ 1: pp. 106115.

SlOAN, James (2005): "Why Anti-Money Laundering Programs Fail", ABA Bank Compliance, vol. 26 no 8: p. 22

UnidAd De ANÁlisis FinANCIERO (2007): Señales de Alerta Indiciarias de Lavado o Blanqueo de Activos para el Sistema Financiero y Otros Sectores, Disponible en: <http:// www.uaf.cl> [Fecha de consulta: 4 de abril de 2008]

VillaVieja, Lucía (2007): "Análisis comparativo de los sistemas preventivos de lucha contra el blanqueo de capitales en Estados Unidos y Europa”, en Comunicaciones presentadas en área 4. Relaciones financieras internacionales. IX Reunión de Economía Mundial, Disponible en: <http://www.uam.es/otros/ixrem/Comunicaciones/04-13VILLAVIEJA.pdf > [Fecha de consulta: 4 de abril de 2008]

ZaGARIS, Bruce (2002): "The Merging of the Counter Terrorism and Anti-Money Laundering Regimes", Law and Policy in International Business, Vol. 45 no 1: pp. 45108.

\section{ÍNDICE DE REGULACIÓN SECTORIAL}

\section{SUPERINTENDENCIA DE ADMINISTRADORAS DE FONDOS DE PENSIONES.}

Circular No 1480, de 28 de diciembre de 2007, dictada conjuntamente con la Unidad de Análisis Financiero. Para este último servicio, dicha Circular aparece bajo el No 0036. 


\section{SUPERINTENDENCIA DE BANCOS E INSTITUCIONES FINANCIERAS.}

Capítulo 1-14 de la Recopilación de Normas de la Superintendencia de Bancos e Instituciones Financieras, cuyo contenido fue fijado por la Circular No 3351 de dicho organismo, de 6 de marzo de 2006.

\section{CIRCULARES:}

No 57 y 58, de 20 de julio de 2006, aplicable a las empresas de leasing y factoraje filiales de bancos;

No 123, de 6 de julio de 2006, aplicable a las cooperativas de ahorro y crédito.

\section{SUPERINTENDENCIA DE CASINOS DE JUEGO.}

Circular No 3, de 23 de julio de 2007, formulada conjuntamente con la Unidad de Análisis Financiero. Para este último servicio, dicha Circular aparece bajo el No 0024.

\section{SUPERINTENDENCIA DE VALORES Y SEGUROS. CIRCULARES:}

No 1809 , de 10 de agosto de 2006;

No 1853 , de 2 de octubre de 2007, que modifica la anterior.

\section{UNIDAD DE ANÁLISIS FINANCIERO: CIRCULARES:}

No 0002, de 18 de mayo de 2005, dirigida a las casas de cambio.

No 0006, de 29 de septiembre de 2005, dirigida a los bancos;

No 0007, de 6 de marzo de 2006, dirigida a los sujetos obligados distintos a los bancos y casas de cambio);

No 0008, de 31 de mayo de 2006, dirigida a todos los sujetos obligados;

No 0009 , de 23 de agosto de 2006, dirigida a todos los sujetos obligados;

No 0010, de 5 de septiembre de 2006,dirigida a todos los sujetos obligados;

No 0011, de 5 de septiembre de 2006, dirigida a todos los sujetos obligados;

No 0012, de 5 de septiembre de 2006, dirigida a los bancos;

No 0013, de 5 de septiembre de 2006, dirigida a las empresas de transferencia y transportes de valores y dinero;

No 0015, de 22 de noviembre de 2006, dirigida a empresas de transporte de valores reguladas por el Decreto exento $\mathrm{N}^{\circ} 1.226$ del Ministerio del Interior;

No 0016, de 28 de diciembre de 2006, dirigida a los bancos;

No 0017 , de 8 de marzo de 2007, dirigida a las casas de cambio;

No 0018, de 11 de mayo de 2007, dirigida a las casas de cambio, empresas de transferencia de dinero y empresas de transporte de valores y dinero;

No 0019, de 22 de mayo de 2007, dirigida a los sujetos obligados distintos a los bancos y casas de cambio;

No 0020, de 14 de junio de 2007, dirigida a las empresas de factoraje;

No 0021, de 14 de junio de 2007, dirigida a las empresas de arrendamiento financiero;

No 0022, de 21 de junio de 2007, dirigida a las cooperativas de ahorro y crédito; 
No 0023, de 11 de julio de 2007, dirigida a los sujetos obligados distintos a los bancos y casas de cambio; No 0024, de 23 de julio de 2007, dirigida a los casinos y sociedades operadoras de casinos;

No 0025 de la UAF, de 13 de agosto de 2007, dirigida a todos los sujetos obligados;

No 0026, de 16 de agosto de 2007, dirigida a las administradoras de fondos de inversión;

No 0027 , de 16 de agosto de 2007, dirigida a las administradoras de fondos mutuos;

No 0028 , de 16 de agosto de 2007, dirigida a las administradoras generales de fondos;

No 0029, de 16 de agosto de 2007, dirigida a las compañías de seguros;

No 0030, de 16 de agosto de 2007, dirigida a los corredores de bolsa;

No 0031 , de 16 de agosto de 2007, dirigida a los agentes de valores;

No 0032, de 7 de septiembre de 2007, dirigida a las emisoras de tarjetas de crédito y operadoras de las mismas;

No 0033, de 30 de agosto de 2007, dirigida a las empresas de securitización;

$\mathrm{N}^{\circ} 0034$, de 25 de octubre de 2007, dirigida a sujetos obligados no financieros, distintos a usuarios de zonas francas;

No 0035, de 19 de noviembre de 2007, dirigida a todos los sujetos obligados; y,

$\mathrm{N}^{\circ} 0036$, de 28 de diciembre de 2007, dirigida a las administradoras de fondos de pensiones. 
